\title{
Los mecanismos de resolución alterna de conflictos en el Derecho cooperativo nicaragüense ${ }^{1}$
}

\author{
(Alternative dispute resolution mechanisms \\ in Nicaraguan cooperative law)
}

\author{
William Torrez Peralta² \\ Universidad Centroamericana, Managua (Nicaragua)
}

Sumario: Introducción. 1. Planteamiento. 2. Los sistemas alternativos de resolución de conflictos en el Derecho nicaragüense. 2.1. La conciliación. 2.2. La mediación. 2.3. El arbitraje. 3. Problemática que se suscita en la ejecución del laudo arbitral. 3.1. La firmeza del laudo. El denominado «recurso de nulidad» del laudo. 3.2. El laudo arbitral en la norma nicaragüense como título ejecutivo extrajudicial. 4. La resolución de conflictos en la legislación cooperativa nicaragüense. 4.1. Breve evolución de los mecanismos alternos de solución de conflictos en el Derecho cooperativo. 4.2. La resolución de conflictos en la legislación cooperativa vigente. 5 . Referencias generales sobre la resolución de conflictos en el Derecho cooperativo Iberoamericano. 5.1. México. 5.2. Costa Rica. 5.3. Panamá 5.4. Colombia. 5.5. Bolivia. 6. Conclusiones. 7. Bibliografía.

Summary: Introduction. 1. Approach. 2. Alternative conflict systems in Nicaraguan law. 2.1. The conciliation. 2.2. Mediation. 2.3. The arbitration. 3. Problems that arise in the execution of the arbitration award. 3.1. The finality of the award. The so-called «appeal for annulment» of the award. 3.2. The arbitration award in Nicaraguan law as an extrajudicial executive title. 4. Conflict resolution in Nicaraguan cooperative legislation. 4.1. Brief evolution of alternative dispute resolution mechanisms in cooperative law. 4.2. The resolution of conflicts in the current cooperative legislation. 5. General references on conflict

1 Este trabajo es el resultado de la estancia de investigación postdoctoral realizada en el Departamento de Ciencias Jurídicas de la Facultad de Derecho de la Universidad de Alcalá, Madrid, dentro del «Programa Giner de Los Ríos para Profesores e Investigadores Invitados» en el período 11/02/2019 a 10/04/2019, bajo la dirección de la Dra. María Marcos González, Catedrática de Derecho procesal de la UAH.

2 Doctor en Derecho por la Universidad de Deusto. Profesor de Derecho procesal. Email: wtperalta@gmail.com. Líneas de investigación: Derecho procesal y sistemas alternativos de resolución de conflictos. 
resolution in Ibero-American cooperative law. 5.1. México. 5.2. Costa Rica. 5.3. Panama. 5.4. Colombia. 5.5. Bolivia. 6. Conclusions. 7. Bibliography.

Resumen: La vía jurisdiccional juega un papel fundamental en los Estados de Derecho, constituyéndose como pilar fundamental en las democracias modernas. A pesar de ello, se ha demostrado que en ciertos ámbitos, la judicialización de los conflictos no conlleva una respuesta adecuada. Los métodos alternativos de conflictos se presentan como modelos más flexibles, caracterizados por su sencillez, prontitud y búsqueda de entendimiento entre las partes más que de confrontación. El Derecho cooperativo es ámbito idóneo para la aplicación de estos mecanismos. Nicaragua no ha sido ajena a estas figuras alternativas de resolución de controversias en este ámbito. Sin embargo, solo una correcta regulación aunada a una profusa información y capacitación de todos los operadores serán la clave para una aplicación real y efectiva.

Palabras clave: Jurisdicción, Derecho cooperativo, resolución alterna de conflictos, justicia, Nicaragua.

Abstract: The jurisdictional route plays a fundamental role in the rule of law, constituting itself as a fundamental pillar in modern democracies. Despite this, it has been shown that in certain areas, the judicialization of conflicts does not entail an adequate response. Alternative conflict methods are presented as more flexible models, characterized by their simplicity, promptness and search for understanding between the parties rather than confrontation. Cooperative law is the ideal environment for the application of these mechanisms. Nicaragua has not been alien to these alternative dispute resolution figures in this area. However, only correct regulation coupled with profuse information and training for all operators will be the key to a real and effective application.

Keywords: Jurisdiction, Cooperative law, alternative dispute resolutions, justice, Nicaragua. 


\section{Introducción}

En los últimos años, en el ordenamiento jurídico nicaragüense ha habido importantes esfuerzos para promover el uso de los métodos alternos de resolución de conflictos llamados universalmente como mecanismos Alternative Dispute Resolution (en adelante, ADR) ${ }^{3}$. En este sentido, se han aprovechado las reformas legales para introducir estos mecanismos en textos tales como en el Código de Familia, Código Procesal Civil, Código Procesal del Trabajo y la Seguridad Social, entre otros. Sin embargo, en el Derecho cooperativo no se ha abordado esta institución con rigor. Esta situación supone un desafío para los académicos, movimiento cooperativo, políticos, organismos no gubernamentales, empleadores, trabajadores, Poderes públicos, etc.

Para abordar esta problemática, es necesario tener presente que en la actualidad el marco regulador de los ADR en el ordenamiento jurídico nicaragüense es la Ley 540/2005 de 25 de mayo, de Mediación y Arbitraje $^{4}$ (en lo sucesivo, LMA) ${ }^{5}$ que reconoce el derecho de toda persona física o jurídica de acudir a los procesos alternos de resolución de controversia con las excepciones establecidas en la Ley. Por ello, conviene tener presente que estos mecanismos son extensivos al Derecho cooperativo.

En cuanto al Derecho cooperativo, la Ley 499/2004 de 29 de septiembre, General de Cooperativas de Nicaragua6 (en adelante, LGC) no hace mención alguna a los ADR, limitándose a señalar que los estatutos determinaran el procedimiento a seguir para resolver sus diferencias o conflictos.

Ante este panorama en el presente trabajo se propone abordar un análisis detallado de los distintos mecanismos para la resolución de

3 Recuérdese que los ADR aparecen en Estados Unidos en los años 30 del siglo xx como consecuencia del movimiento de libre acceso a la justicia. El objetivo de este se movimiento fue la búsqueda de alternativas a los tribunales de justicia, que fue evolucionando y fue asumido por el sistema jurídico norteamericano. Por tanto, las ADR tienen un origen eminentemente anglosajón. Barona Vilar, Silvia. 2011. "Las ADR en la justicia del siglo XXI, en especial la mediación». Revista de Derecho 1: 192193. https://scielo.conicyt.cl/scielo.php?pid=S071897532011000100008\&script=sci_ arttext\&tIng=en

${ }^{4}$ La Gaceta Diario Oficial n. ${ }^{\circ} 112$ de 24 de junio de 2005.

5 Con anterioridad a la aprobación de la Ley 540/2005 de 25 de mayo, de Mediación y Arbitraje, regía en esta materia la Ley General sobre Cámaras de Comercio de 3 de mayo de 1934; el Código de Procedimiento Civil de 1905 que establecía en su título XIII del Libro tercero de la Jurisdicción Contenciosa los llamados «juicios por arbitramiento»; y el Código Civil regulaba el denominado contrato de «compromiso».

${ }^{6}$ La Gaceta Diario Oficial n. ${ }^{\circ} 17$ de 25 de enero de 2005. 
controversias establecidos en la normativa nicaragüense lo que nos llevará a concluir que estos métodos se adecúan mejor a la realidad cooperativa frente a la vía jurisdiccional.

El trabajo está estructurado de la siguiente manera: en primer lugar, planteamos con carácter general el derecho de acceso a la justicia como principio fundamental y el papel que desempeñan los ADR como parte de este derecho. Seguidamente abordamos los ADR desde el Derecho nicaragüense vigente, donde también entramos a analizar la problemática que se suscita en la ejecución forzosa del laudo arbitral.

En el apartado siguiente entramos a analizar la resolución de conflictos según la legislación cooperativa nicaragüense, exponiendo el escenario desde su inicios, evolución y estado actual de las mismas.

Posteriormente, dedicamos el siguiente espacio a analizar de manera breve la legislación en algunos países Iberoamericanos respecto a los ADR en el ámbito cooperativo con el objeto de encontrar en ellas algunas novedades dignas de ser incorporadas en una hipotética reforma legal en Nicaragua. Para ello presentamos los sistemas de México, Costa Rica, Panamá, Colombia y Bolivia.

Por último, cerramos este trabajo con unas conclusiones.

\section{Planteamiento}

Si bien en las últimas décadas ha habido importantes esfuerzos en el continente Iberoamericano tendientes a asegurar el acceso a la justicia, ya sea por disposición expresa de las propias Constituciones o como obligación impuesta derivadas de Tratados internacionales a los que se han venido adhiriendo, se mantiene un importante déficit en este rubro.

No obstante, el acceso a la justicia sigue mostrando dificultades en su práctica: el retraso jurisdiccional, los costes económicos de los procesos, la dificultad en los desplazamientos que se refuerza por la compleja geografía dada la ubicación física de los tribunales, sobre todo en las grandes ciudades, politización de los tribunales, entre otras. Estudios realizados por organismos internacionales muestran incluso un retroceso en el acceso a la Justicia, derivada de diversos factores ${ }^{7}$.

7 El más reciente estudio realizado por el World Justice Project sobre el «Estado de Derecho $2020 »$ nos ofrece un interesante trabajo estableciendo ya categorías no solo sociales y normativas sino también de evidencia práctica en algunos puntos concretos, como «retrasos injustificados en la justicia». Este informe presenta unos índices muy ba- 
Aunque como decíamos en la introducción las reformas procesales implementadas en los últimos años han aportado soluciones parciales para agilizar los conflictos jurisdiccionales, hace falta complementarlas con otros sistemas alternativos que garanticen la obtención de justicia, la convivencia social, alejando la conflictividad que muchas veces se prolonga demasiado en el tiempo, entorpeciendo el desarrollo social y económico de las comunidades.

Ahora bien, los ADR no son la panacea ni mucho menos afirmamos que con ellos se va a pretender acabar con todos los problemas de la justicia. Sin embargo, y por las razones que después expondremos, estos medios de resolución de conflictos carecen de los formalismos y cargas que juegan como factores de reticencia a una población que ya sufre otro tipo de déficits y carencias, convirtiendo la vía jurisdiccional en una pesada carga al ciudadano.

Ante esta situación, el derecho de acceso a la justicia ha tenido que reinventarse con el objeto de garantizar su propio objetivo que es dar respuesta oportuna y en justicia a los ciudadanos teniendo en cuenta sus propias peculiaridades, necesidades y limitaciones. De este modo, la legislación nicaragüense ha ido poniendo a disposición del ciudadano otros medios para que la población pueda gestionar sus controversias y poder optar por aquél que más se adapte a sus intereses. Por tanto, si las partes en una disputa eligen alguna vía alternativa para intentar resolver la misma lo harán de forma consciente y voluntaria, y porque entiendan que esta es más adecuada o les ofrece mayores ventajas que el proceso jurisdiccional.

No se trata de denostar al sistema adversarial clásico vigente en los ordenamientos jurídicos de corte continental y que ha supuesto y supone una forma de resolución de conflictos que ha dado respuesta satisfactoria a la garantía de derechos fundamentales dentro de los estados llamados de Derecho. Entendemos que su déficit no viene ocasionado tanto por su naturaleza como en su puesta en práctica en ciertos espacios. Y es en este sentido en que otros mecanismos de resolución de controversias pueden jugar un papel fundamental, siempre que sean concebidos como métodos que han de venir a resolver las deficiencias del sistema imperante. Solo de este modo, podríamos afirmar que el derecho de acceso a la Justicia es efectivo y cumple con sus objetivos propuestos que no es sino hacer llegar a la Justicia a to-

jos para Nicaragua con respecto a los rubros de «justicia civil» y «justicia penal», ubicando a este país por debajo de la media tanto a nivel global como regional. World Justice Project. 2020. Índice de Estado de Derecho 2020. Washington, DC. https:// worldjusticeproject.org/sites/default/files/documents/WJP-Global-ROLI-Spanish.pdf 
dos los rincones del país, integrando a los ADR al sistema de administración de Justicia8.

En su dimensión normativa, el acceso a la justicia se relaciona con derechos reconocidos en instrumentos internacionales de derechos humanos $^{9}$. En este sentido, el acceso a la justicia se considera como uno de los derechos fundamentales que consagra el artículo 14 del Pacto Internacional de Derechos Civiles y Políticos en plena sintonía con el art. 8.1 de la Convención Americana sobre Derechos Humanos $^{10}$, y que fue recogido en el artículo 34 de la Constitución nicaragüense (en los sucesivo, CN).

La CN consagra el derecho a la tutela judicial efectiva que es definido por la doctrina como el libre acceso a los órganos jurisdiccionales para solicitar de estos la tutela de un derecho subjetivo y obtener una resolución de fondo fundada en Derecho ${ }^{11}$. Si bien es cierto que la norma suprema nicaragüense en su artículo 159 párrafo segundo atribuye en exclusiva al Poder judicial, la función de «juzgar y ejecutar lo juzgado», diversas reformas posteriores han venido incorporado los ADR a la realidad jurídica del país. De este modo, estos otros mecanismos de resolución alterna de conflictos no vulneran el derecho a la tutela judicial efectiva recogido en el artículo $34 \mathrm{CN}$, sino que forman parte de ella12.

El legislador nicaragüense incorporó por primera vez los ADR al texto constitucional en la Ley 854/2014 de 29 de enero de reforma parcial a la Constitución ${ }^{13}$ en el párrafo segundo del art. 160, disposición que hace referencia al principio de legalidad y en concreto haciendo alusión a las comunidades indígenas al señalar que «la administración de justicia reconoce la participación ciudadana a través de los líderes tradicionales de los pueblos originarios de la Costa Caribe y los facilitadores judiciales en todo el país, como métodos alternos de

8 Otero Parga, Milagros. y Sotelo Muñoz, Helena. 2007. Mediación y solución de conflictos, habilidades para una necesidad emergente. Madrid: Tecnos.

9 Cappelletti, Mauro. y Bryant Garth. 1996. El acceso a la justicia. La tendencia en el mundo mundial para hacer efectivos los derechos. México: Fondo de Cultura Económica.

10 Conocida también como Pacto de San José de 22 de noviembre de 1969.

11 Díez-Picazo, Luis María. 2013. Sistema de derechos fundamentales. Pamplona: Thompson-Civitas. En el mismo sentido, Pérez-Villalobos, María Concepción. 2017. «Artículo 24.1 CE: Tutela judicial efectiva». En Derechos fundamentales, aspectos básicos y actuales. Santiago de Compostela: Andavira Editora. 400-401.

12 Barona Vilar, Silvia. 2014. «Integración de la mediación en el moderno concepto de Acces to Justice. Luces y sombras en Europa». Revista para el análisis del Derecho 4: 6. https://www.raco.cat/index.php/InDret/article/view/291746/380245

13 La Gaceta Diario Oficial n. ${ }^{\circ} 26$ de 10 de febrero de 2014. 
acceso a la justicia y resolución alterna de conflictos, de conformidad con la ley».

Al año siguiente, se aprueba la Ley 902/2015 de 5 de agosto de Código Procesal Civil ${ }^{14}$ (en lo sucesivo CPCN), la cual instaura una mediación previa con carácter obligatoria a las partes antes iniciar cualquier proceso jurisdiccional, señalando el art. 407 párrafo primero: «Antes de interponer la demanda, las partes deberán acudir a las sedes de la Dirección de Resolución Alterna de Conflictos o a un centro de mediación autorizado y supervisado por dicha dirección, a procurar resolver el conflicto a fin de evitar el inicio del proceso» ${ }^{15}$.

Por su parte la Exposición de Motivos de dicho Código expresa que la «mediación constituirá un presupuesto procesal previo a la iniciación de los procesos excepto para la Ejecución Forzosa de títulos judiciales, con lo que se pretende propiciar una cultura de paz en las personas, de autodeterminación, es decir, de un ejercicio pleno de sus capacidades para resolver por sí mismas sus conflictos». Únicamente, cuando las partes no llegaran a un acuerdo, el art. 407 párrafo tercero del mismo texto señala que: «el solicitante de la mediación podrá acudir ante el juzgado civil competente a efecto de plantear su demanda, debiendo acompañar la constancia emitida por la Dirección de Resolución Alterna de Conflictos o el centro administrador de métodos de resolución alterna de conflictos indicando que se efectuó la convocatoria al trámite o su celebración sin existir acuerdo».

Los ADR han hecho su incursión en el ordenamiento jurídico nicaragüense de forma decidida en su legislación, abarcando una buena parte de la materia regulada. Las razones a su incorporación no pueden achacarse a un único motivo. La congestión de los tribunales es una razón de peso para su aprobación, pero no la única en un país donde, como ya señalábamos, tiene condiciones geográficas, sociales, culturales y económicas que animan a buscar formas de resolución más flexibles, rápidas y económicas que nos lleven a una convivencia social más justa.

14 La Gaceta Diario Oficial n. ${ }^{\circ} 191$ de 9 de octubre de 2015.

15 El antecedente inmediato de este precepto se encuentra en la Ley Orgánica 260/1998 de 7 de julio, del Poder Judicial, al prescribir en su art. 94 párrafo primero: «En todos los casos en que se presenten demandas de familia, civiles, mercantiles, agrarias y laborales en los juzgados respectivos, previo a cualquier actuación o diligencia, el juez convocará dentro de sexto día a un trámite de mediación entre las partes las que podrán estar asistidas por abogados». 


\section{Los sistemas alternativos de resolución de conflictos en el Derecho nicaragüense}

Decíamos anteriormente que en el año 2005 se aprueba la Ley 540 de 25 de mayo de Mediación y Arbitraje que reconoce en su artículo primero el derecho de toda persona física o jurídica de acudir a los procesos alternos de resolución de controversia con las excepciones establecidas en la propia Ley (esta norma constituye el fundamento jurídico para el uso de los ADR en el Derecho cooperativo).

Estos mecanismos de resolución de controversias están sometidos a una serie de principios que la norma recoge en su artículo 3 y que son la voluntariedad, imparcialidad, equidad y confidencialidad. La voluntariedad es clave para la aplicación de este tipo de métodos alternos, que tiene su fundamento en el principio de la autonomía de la voluntad, entendida esta como el poder reconocido a toda persona para conformar libremente una relación jurídica, siempre que no sea contraria a las leyes, a la moral ni al orden público ${ }^{16}$.

Sin duda alguna, este principio de la autonomía de la voluntad está íntimamente ligado al criterio de disponibilidad del objeto litigioso. Así lo determina el art. 23 de la LMA: "La presente Ley se aplicará en todos aquellos casos en que la controversia verse sobre materias en que las partes tengan libre disposición conforme a derecho [...]».

Sin perjuicio de lo estipulado en la LMA, la mediación viene establecida también en el artículo 406 CPCN, al expresar que: "La mediación y cualquier otra forma alterna de resolución de conflictos se aplicarán en lo que corresponda, a las controversias civiles, de conformidad con lo dispuesto en este Código y leyes de la materia. A tal efecto las partes podrán hacer uso de los distintos métodos de resolución de conflictos en las sedes de la Dirección de Resolución Alterna de Conflictos, o en un centro administrador de métodos de resolución alterna de conflictos autorizado y supervisado por la Dirección de Resolución Alterna de Conflictos».

En cuanto al poder de disposición de estos métodos alternos, el artículo 96 del CPCN reconoce el poder de disposición de las partes en el proceso, al señalar que «las partes podrán disponer de las pretensiones interpuestas en el proceso, en cualquier momento de sus instancias y aún en casación, o en la ejecución forzosa, siempre con-

16 Herrera de las Heras, Ramón. 2012. «La autonomía de la voluntad en el arbitraje y la mediación. Jurisprudencia constitucional española y experiencias en el ámbito de consumo». Revista de Derecho 12: 179. https://scielo.conicyt.cl/scielo.php?script=sci_art text\&pid=S0718-09502012000100008 
forme a la naturaleza de cada acto de disposición. A tal efecto, las partes podrán poner fin al proceso, por carencia sobrevenida del objeto del proceso o por satisfacción extraprocesal, renunciar, desistir, allanarse, someterse a arbitraje y transigir sobre lo que sea objeto del mismo, así como por abandono por falta de actividad procesal de las partes. De lo dispuesto en el punto anterior, se exceptuarán los casos en los que la ley prohíba la disposición o la limite por razones de orden público, de interés general, de protección de terceros, o cuando implique fraude de ley».

Establecido el principio de voluntariedad, la LMA presenta una lista abierta de ADR entre los cuales las partes podrán elegir el que más le convenga. Las figuras más representativas ya sea por su más extensa regulación en las normas o por su mayor uso por la comunidad se reducen a tres: conciliación, mediación y arbitraje. Procedemos a su breve análisis desde el Derecho nicaragüense.

\subsection{La conciliación}

\section{CONCEPTO Y CLASES}

La conciliación es definida como aquel mecanismo de resolución de controversias en el que las partes, con plena autonomía de la voluntad y siempre que las normas lo permitan, comparecen ante un tercero - conciliador - quien facilita el acuerdo sin resolver y limitándose a sugerir y proponer soluciones ${ }^{17}$. Estamos, por tanto, frente a un acto jurídico negocial a través del cual se realiza una transacción entre las partes. Es la voluntad de estas la que determina la resolución del conflicto. El conciliador propone recomendaciones a las partes que estos pueden aceptar o no ${ }^{18}$. Al conciliador no se le exige un conocimiento en técnicas de autocomposición, siendo que su papel, como señala BARONA VILAR, «es trabajar conjunta y separadamente con las partes para que sean estas las que asuman el verdadero papel de conformadores del acuerdo» ${ }^{19}$.

En definitiva, la conciliación se concibe como un mecanismo autocompositivo, en virtud del cual las partes, con base en la autono-

17 Montoya Melgar, Alfredo. 2020. Derecho del trabajo. Madrid: Tecnos.

18 Argudo Périz, José Luis. 2006. "Los sistemas no adversariales de resolución de conflictos en la legislación cooperativa autonómica». Revista vasca de economía socialGEZKI 2: 106. https://ojs.ehu.eus/index.php/Gezki/article/view/3296/2922 En el mismo sentido, Montoya Melgar 2020, 770.

19 Barona Vilar, Silvia 2014, 8. 
mía de la voluntad y siempre que se trate de una materia disponible, evitan el comienzo de un proceso jurisdiccional o ponen fin al ya comenzado.

La conciliación es el ADR por excelencia del Derecho del trabajo nicaragüense estando presente en todos los conflictos que se susciten con motivo de las relaciones laborales. Esta presencia de la conciliación en el Derecho laboral contrasta con su ausencia explícita en el resto de normas, lo que nos obliga a analizar esta figura únicamente desde su perspectiva del Derecho laboral.

La Ley 815/2012 de 31 de octubre, de Código Procesal del Trabajo y de la Seguridad Social ${ }^{20}$ (en adelante, CPTSS) introduce innovaciones al determinar tanto la conciliación administrativa previa a la vía jurisdiccional como la conciliación intraprocesal, todo ello con el fin de encaminar la resolución de la disputa a la conciliación, evitando así el congestionamiento de los tribunales sociales.

La legislación procesal laboral nicaragüense distingue dos clases de conciliación: conciliación previa o preprocesal y la conciliación intraprocesal.

\section{a. Conciliación previa}

Esta es una actividad preprocesal que se impone como requisito para iniciar el proceso laboral de menor cuantía «en los demás casos será opcional acudir en conciliación a la vía administrativa» (art. 72.1 (PTSS) ${ }^{21}$. Esta conciliación tiene un carácter preventivo, tendiendo a evitar el proceso 22 .

Esta conciliación se desarrolla conforme al procedimiento siguiente:

i. Se concilia ante el órgano administrativo competente, que es el Ministerio del Trabajo.

20 La Gaceta Diario Oficial n. ${ }^{\circ} 229$ de 29 de noviembre de 2012

21 Sin perjuicio de las disposiciones que señala el CPTSS sobre la conciliación administrativa previa, se aprobó el Acuerdo Ministerial 019-12-08/2008 de 10 de diciembre, que en su artículo 1 señala: «El presente procedimiento regula la tramitación en el Ministerio del Trabajo de las solicitudes de: a) suspensión colectiva de los contratos de trabajo; b) cierre de las empresas y c) cancelación de contrato de trabajo por justa causa, contemplados en los artículos 38, 41 literal d) y 48 del Código del Trabajo. El Inspector Departamental del Trabajo es la autoridad administrativa que conocerá de dicho procedimiento, con la excepción establecida en el art. 9». La Gaceta Diario Oficial n. ${ }^{\circ} 237$ de 12 de 2008.

22 Montero Aroca, Juan, Juan Luis Gómez Colomer, Silvia Barona Vilar y María Pía Calderón Cuadrado. 2017. Derecho jurisdiccional. Proceso civil. Valencia: Tirant lo Blanch. 
ii. La solicitud del trámite conciliatorio ante la autoridad administrativa puede ser de forma oral o escrita, en la que se identificarán las partes, se expondrán los hechos sobre lo que se pretenda conciliar.

iii. Citación a las partes. De la presentación de la solicitud la autoridad competente notificará a la parte contraria para que en el plazo de diez días comparezca al acto conciliatorio. Si el peticionario de la conciliación no comparece en el día y hora señalada se tendrá por no intentada la conciliación. «Si la incomparecencia ha sido por causa grave podrá solicitar la fijación de nueva fecha, justificándola dentro de tercero día ante el órgano de conciliación administrativa».

iv. La presentación de la solicitud de conciliación suspende el plazo de caducidad e interrumpe la prescripción.

v. La incomparecencia del demandado o ausencia de acuerdo entre las partes son presupuestos obligatorios, en cada caso, para interponer la correspondiente demanda en la vía jurisdiccional. «La inasistencia al acto de conciliación no interrumpe la prescripción» (art. 72.4 CPTSS). Recuérdese que la norma del precepto 72.5 CPTSS, determina que «es obligatoria la concurrencia al acto de conciliación de la parte a quien se reclama. Si no comparece sin justificación, se tendrá por intentada sin efecto; pero si presentare justificación suficiente por su inasistencia dentro del plazo a que se refiere este artículo, podrá ser citado por segunda vez».

vi. Si hay avenencia. Lo que se acuerde en la conciliación constituye título ejecutivo para iniciar la ejecución forzosa sin necesidad de ratificación del juez laboral, es decir, se procede directamente a la ejecución forzosa.

\section{b. Conciliación intraprocesal}

La conciliación intraprocesal es aquel mecanismo autocompositivo que el juez ofrece a las partes cuando ya se ha iniciado un proceso jurisdiccional ${ }^{23}$, surgiendo una litispendencia. En este caso, el proceso laboral nicaragüense se desarrolla en una sola audiencia.

Así, el artículo 85 del CPTSS dispone «1. En el día señalado, constituido en audiencia pública, confirmada la presencia de las partes o sus

23 Monereo Pérez, José Luis. 2020. Manual de Derecho procesal laboral: teoría y práctica. Madrid: Tecnos. 
representantes, la autoridad judicial les exhortará a flexibilizar sus respectivas posturas y a buscar una solución negociada, indicando con propiedad las ventajas procesales de esta alternativa, pero evitará emitir criterios o valoraciones de fondo sobre ellas. En ese sentido, invitará a la parte demandada a efectuar una oferta que razonablemente pueda ser aceptada por la demandante. Las partes si así lo desean podrán también sugerir las alternativas o soluciones que estarían dispuestas a admitir o adoptar, teniendo la autoridad judicial la obligación de tratar de acercar las posiciones expresadas por cada una de ellas, pero cuidando que el acuerdo que pudiera producirse no entrañe abuso o fraude a la Ley; 2 . La autoridad judicial de la causa, garantizará que los acuerdos no vulneren las garantías básicas contenidas en la legislación laboral vigente, por lo que no los aprobará cuando aprecie motivadamente en la correspondiente acta que es constitutivo de lesión grave para alguna de las partes, de fraude de Ley o de abuso de derecho o posición dominante; y 3. En caso que no haya acuerdo así se hará constar en el acta. La autoridad judicial al momento de dictar su sentencia no deberá considerar lo actuado en el intento de conciliación».

Como se puede observar en este acto del juicio oral, el juez conciliador no resuelve la controversia sino que se limita a tratar de aproximar las posturas encontradas de las partes.

\subsection{La mediación}

\section{CONCEPTO Y CLASES}

El artículo 4 de la LMA define a la mediación como «todo procedimiento designado como tal, o algún otro término equivalente, en el cual las partes soliciten a un tercero o terceros, que les preste asistencia en su intento por llegar a un arreglo amistoso de una controversia que se derive de una relación contractual u otro tipo de relación jurídica o esté vinculada a ellas. El mediador no estará facultado para imponer a las partes una solución de la controversia», ni tampoco para proponer posibles soluciones sino que nos encontramos ante un tercero neutral (mediador) que tiene como función facilitar las negociaciones entre las partes en conflicto con el fin de llegar a una solución aceptable para ellas $^{24}$. La mediación como señala VALIÑO CES viene a suministrar a las

24 Ramos Pérez, María Eugenia. 2006. «La gestión de conflictos en las cooperativas». Revista vasca de economía social-GEZKI 2: 146. https://dialnet.unirioja.es/servlet/ articulo? codigo $=2234218$ 
partes en conflicto un contexto tranquilo y neutral donde puedan conversar acerca del modo de solventar sus diferencias, responsabilizándose de sus decisiones y abriendo una vía para que puedan seguir relacionándose en el futuro ${ }^{25}$.

En el ordenamiento jurídico nicaragüense el Código Procesal Civil distingue dos tipos de mediación en atención al momento procesal en que la misma se produce: mediación previa y mediación intraprocesal que a continuación explicamos:

\section{a. Mediación previa}

La mediación previa al proceso constituye una actuación necesaria para las partes que pueden utilizar, antes de acudir al proceso. Este tipo de mediación, en todo caso tiene carácter obligatorio o necesario para el ejercicio de los derechos en el ámbito del proceso civil ${ }^{26}$. El legislador nicaragüense ha otorgado a esta institución la categoría de presupuesto de admisión de demanda. Así se refiere el artículo 407 párrafo primero CPCN: "Antes de interponer la demanda, las partes deberán acudir a las sedes de la Dirección de Resolución Alterna de Conflictos o a un centro de mediación autorizado y supervisado por dicha dirección, a procurar resolver el conflicto a fin de evitar el inicio del proceso».

La mediación previa al proceso es preventiva pues busca evitar el proceso y tiene un carácter general. Es un medio de autocomposición ofrecido a las partes en un conflicto. Si se resuelve el conflicto se pone fin a la disputa, mientras que si el resultado es negativo, las partes pueden acudir a la vía jurisdiccional.

\section{b. Mediación intraprocesal}

La mediación intraprocesal, a diferencia de la anterior, no tiene en ningún caso carácter obligatorio para el ejercicio de los derechos. El artículo 408 párrafo primero CPCN dispone: «Durante el proceso civil y aún en la fase de ejecución, las partes podrán acudir a la Dirección de

25 Valiño Ces, Almudena. 2019. «Más allá de los métodos alternativos clásicos al proceso judicial: otras formas de resolución de conflictos». Cuadernos de Dereito actual 11: 208. http://www.cadernosdedereitoactual.es/ojs/index.php/cadernos/article/ view/381

${ }^{26}$ Esto no significa que sea obligatorio llegar a un acuerdo en la mediación puesto que el principio de autonomía de la voluntad no lo permite, ya que la mediación previa no obliga a las partes en conflicto a alcanzar ningún acuerdo. Por tanto, este tipo de mediación no va contra un elemento básico de ella, que es la voluntariedad. 
Resolución Alterna de Conflictos o a un centro administrador de métodos alternos de conflictos, autorizado y supervisado por aquella, en búsqueda de acuerdo, previa solicitud de suspensión del proceso por acuerdo de las mismas, conforme lo establecido en este Código». En este supuesto, si realizado este intento de mediación las partes no llegan a un acuerdo, el proceso jurisdiccional continuará su curso.

\section{Procedimiento de la mediación}

La mediación se estructura en el siguiente procedimiento que determina la Ley de Mediación y Arbitraje:

\section{a. Petición}

El artículo 8 de la LMA señala que «el procedimiento de mediación relativo a una determinada controversia dará comienzo el día en que las partes acuerden iniciarlo. La parte que haya invitado a otra a entablar un procedimiento de mediación y no reciba de esta última una aceptación de la invitación en el plazo de quince días a partir de la fecha en que envió esta, o en cualquier otro plazo fijado en ella, podrá considerar que la otra parte a rechazado su oferta de mediación».

De conformidad con el art. 9 de la LMA, en la mediación, por la complejidad del asunto a tratar o simplemente porque así lo desearán, podrán intervenir uno o varios mediadores debiendo en este último caso de actuar dichos mediadores de forma coordinada.

La LMA no dice nada expresamente sobre la forma en la cual habrá de realizarse la solicitud para acudir ante un mediador. Únicamente la Dirección Alterna de Conflictos determina en su reglamento que la solicitud habrá de llevarse a cabo por escrito dirigido al mediador o mediadores, o bien mediante la cumplimentación de los formularios que las instituciones de mediación habrán de poner a disposición de las partes para evacuar tal petición.

\section{b. Efectos de la presentación de la petición}

Desde la presentación de la solicitud, el proceso de mediación se activa y comienza a tener una serie de efectos procesales que se regulan tanto en el CPCN como en la LMA.

Se establece una mecánica de relación entre la mediación y el proceso jurisdiccional. La presentación de la solicitud de mediación produce un efecto similar al de litispendencia no pudiendo ejercitar las partes ninguna pretensión judicial o extrajudicial en relación con el 
mismo objeto durante el tiempo en que se desarrolle la mediación ${ }^{27}$. Las únicas excepciones se refieren, por un lado, a la solicitud de adopción de medidas cautelares $u$ otras medidas urgentes para evitar perjuicios irreparables (art. 46 párrafo último CPCN). Por otro lado, el artículo 27 párrafo final del CPCN posibilita a las partes denunciar ante los tribunales la falta de jurisdicción por haberse sometido la controversia a mecanismo alternativo de conflictos, lo que habrá sido realizado en el contrato ${ }^{28}$. La parte demandada habrá de materializar la denuncia de falta de jurisdicción a través de declinatoria. El juez archivará definitivamente el caso si se estima la declinatoria, tal como lo establece el art. 47 CPCN.

En el art. 167 del CPCN se hace referencia igualmente a la posibilidad que tienen las partes de solicitar la suspensión de un proceso judicial abierto si de forma voluntaria deciden iniciar un procedimiento de mediación. El tiempo máximo de suspensión es de sesenta días, si bien, si transcurrido dicho plazo las partes continúan en el procedimiento de mediación, podrían solicitar del juez competente un nuevo aplazamiento del proceso judicial.

En cualquier caso, si transcurriese el plazo de sesenta días y las partes no solicitan al juez un nuevo plazo de suspensión o la reanudación del proceso jurisdiccional, no habría mayores consecuencias, quedando los autos archivados provisionalmente del expediente, «el que permanecerá en tal situación mientras no se solicite la continuación del proceso o se produzca la caducidad de la instancia» (art. 167 párrafo último CPCN).

Otro de los efectos de la presentación de la solicitud de mediación es la suspensión de la prescripción de acciones desde la fecha en la que conste la recepción de dicha solicitud por el Centro Alterno de Conflictos. Si bien la LMA no determina nada al respecto, tenemos que

27 Sotelo Muñoz, Helena, Emiliano Carretero Morales y Cristina Ruiz López. 2017. Mediación y resolución de conflictos: Técnicas y ámbitos. Madrid: Tecnos.

28 En el mismo sentido se expresa el art. 45 CPCN: «Las partes pueden promover la separación por falta de competencia: 1) Por corresponder el conocimiento del asunto a tribunales extranjeros, o a órganos de otro orden jurisdiccional; 2) Ante la existencia de convenio o cláusula válida de sometimiento del conflicto a arbitraje». Y el 18 de la LMA manifiesta: "Cuando las partes hayan acordado recurrir a la mediación y se hayan comprometido expresamente a no entablar, en un determinado plazo o mientras no se produzca cierto hecho, ningún procedimiento arbitral o judicial con relación a una controversia existente o futura, el tribunal arbitral o de justicia dará a efecto a ese compromiso en tanto no se haya cumplido lo en él estipulado, salvo en lo que se respecta a medidas necesarias para la salvaguarda de los derechos que, a juicios de las partes, les correspondan. El inicio de tales medidas no constituirá, en sí mismo, una renuncia al acuerdo de recurrir a la mediación ni la terminación de esta». 
recurrir por analogía al art. 930 del Código Civil que señala: «La prescripción se interrumpe también por cualquier gestión judicial o extrajudicial, para el cobro de la deuda y cumplimiento de la obligación o para el ejercicio de cualquier acción real».

No desconocemos el uso fraudulento que puede hacer una de las partes de esta figura con el objeto de retardar la resolución del conflicto, pudiéndose beneficiar de una extensión de plazo de sesenta días. Sin embargo, hasta ahí puede llegar el beneficio: la suspensión provisional del proceso no computa ni para el ejercicio de la acción ni para el ejercicio de actos procesales ${ }^{29}$.

\section{Citación a las partes}

Una vez presentada la solicitud de inicio de la mediación ante el Centro Alterno, las partes habrán de ser citadas para la sesión de mediación en el más breve plazo de tiempo posible. Si se produce la inasistencia injustificada de alguna de las partes a la sesión de mediación, habrá de entenderse que desisten de la misma, extendiéndose "constancia de inasistencia» para los fines legales que las partes estimen conveniente ${ }^{30}$. El artículo 10 de la LMA permite que las partes conjunta o separadamente puedan solicitar con dos días de antelación a la audiencia de mediación la suspensión de la misma. La misma norma señala que "salvo acuerdo entre las partes, las mismas podrán justificar su inasistencia por una sola vez. Posterior a ello, si no comparece a la audiencia alguna de las partes, se levantará para tal fin, acto por el cual se dará por concluida la actuación del mediador y la mediación misma» (art. 10 párrafo último LMA).

\section{d. Desarrollo de las sesiones}

El mediador será la persona encargada de convocar a las partes y dirigirá en todo momento su desarrollo, condicionándose la duración y estructura a su propia valoración que hará en base a las necesidades de las partes.

La audiencia de mediación se desarrollará en una o varias sesiones con la presencia del mediador y de las partes «o sus apoderados auto-

29 Barona Vilar, Silvia. 2013. Mediación en asuntos civiles y mercantiles en España. Valencia: Tirant lo Blanch.

30 Dirección de resolución alterna de conflictos-Corte Suprema de Justicia de Nicaragua. 2019. Manual curso básico de mediación. Managua: Publicaciones Poder Judicial. 
rizados mediante poder de representación. Los abogados podrán asistir a las partes si estas lo solicitan expresamente» (art. 10 párrafo primero LMA).

El art. 12 de la LMA regula las comunicaciones entre el mediador y las partes al señalar que «el mediador podrá reunirse o comunicarse de forma oral escrita con las partes conjuntamente o con cada una de ellas por separado», bajo la observancia de estrictas normas confidencialidad sobre todo lo tratado en dichas reuniones o comunicaciones. Por tanto, no puede ser utilizada esta información brindada por las partes al mediador a menos que tenga autorización expresa de ella para hacerlo (arts. 13 y 14 LMA).

CARRETERO MORALES señala que el papel del mediador es fundamental llegando a poder condicionar el resultado de la gestión. Según el autor debe comenzarse con una breve explicación sobre su papel: «el mediador explique claramente a las partes qué es la mediación, lo normal es que estas, aunque puedan tener alguna idea o noción sobre la misma, no sepan claramente en qué consiste y por qué han de optar la misma y, en este sentido, es importante que la diferencien nítidamente de otros métodos de solución de conflictos, en particular del proceso judicial. Las partes han de ver y entender las razones por las que la mediación va a resultar adecuada para intentar dar una solución al conflicto que les atañe, por lo que no es suficiente que se explique en abstracto qué es la mediación, cuáles son sus características o sus ventajas, sino que las partes tienen que percibir que por la naturaleza y la circunstancias de su conflicto en particular, la mediación es la mejor vía para intentar resolver el mismo, y es labor fundamental del mediador conseguir tal percepción en las partes»31.

e. Fin del proceso de mediación

Según el artículo 16 de la LMA el procedimiento de mediación se dará por terminado:

i. "Al llegar las partes a un acuerdo y firmarlo».

En primer término, señala la posibilidad de que el procedimiento concluya con un acuerdo voluntario entre las partes.

ii. «Al hacer el mediador, previa consulta con las partes, una declaración por escrito que haga constar que ya no se justifica se-

31 Carretero Morales, Emiliano. 2016. La mediación civil y mercantil en el sistema de justicia Madrid: Dykinson. 
guir intentando llegar a un acuerdo, en la fecha de tal declaración».

Estamos ante un caso de renuncia del mediador. Varias razones pueden suscitar esta decisión, ya sea por considerar que le «representa un conflicto de intereses» [art. 6 numeral 2) LMA] o cuando las partes no están actuando correctamente o haya una evidente situación de desequilibrio entre las partes. Ahora bien, este caso no tiene por qué suponer la finalización de la mediación entre las partes, ya que la renuncia del mediador a continuar el procedimiento solo producirá su terminación cuando no se llegue a nombrar a otro por lo que la decisión de finalizar definitivamente la mediación vuelve a recaer nuevamente en las partes, quienes si no están conformes con la decisión tomada por el mediador, pueden designar uno nuevo a fin de que continúe con el procedimiento iniciado ${ }^{32}$.

iii. «Al hacer las partes al mediador una declaración por escrito de que dan por terminado el procedimiento de mediación, en la fecha de tal declaración».

En tercer término, será un abandono bilateral al determinar que ambas partes le manifestarán al mediador que dan por terminado el proceso de mediación en esa fecha. Esta razón de abandono podrá ser cuando las partes no son capaces de resolver la disputa. También podría ser por el transcurso del plazo máximo acordado para resolver el conflicto, ya que, si bien la LMA no ha optado por fijar un plazo máximo de duración del procedimiento de mediación, no está de más que las partes y el mediador o el Centro Alterno de Conflictos donde se va a llevar adelante determinen un límite temporal del procedimiento de mediación, para impedir a las partes prolongar el procedimiento 33 .

iv. "Al hacer una parte a la otra o las otras partes y al mediador, una declaración por escrito en el que da por terminado el procedimiento de mediación, en la fecha de tal declaración».

Se trata del abandono unilateral por parte de una de las partes. Dado que el sometimiento al procedimiento de mediación es voluntario las partes son libres de abandonarlo desde su inicio y en cualquier momento.

32 Barona Vilar, Silvia 2013, 424-425.

33 Carretero Morales, Emiliano 2016, 284. 


\section{f. Efectos del acuerdo de mediación}

El acuerdo de mediación deberá constar por escrito y en él se contendrán los puntos acordados. Tal acuerdo está llamado a cumplir los efectos obligatorios en él contenidos como así lo señala el art. 20 de la LMA: «El acuerdo al que lleguen las partes en un proceso de mediación será definitivo, concluye con el conflicto y será ejecutable en forma inmediata».

En este caso, tal acuerdo ha de entenderse que tiene el efecto de una transacción en cuanto constituye una composición del litigio encuadrable en el art. 2176 del Código Civil y con los efectos que para la transacción extrajudicial dispone la norma del art. 2193 del mismo Código ${ }^{34}$.

\subsection{El arbitraje}

\section{CONCEPTO Y CLASES}

El artículo 24 inciso a) de la LMA define al arbitraje como el «mecanismo alterno de solución de conflictos que surge de la autonomía de la voluntad de las partes, quienes delegan en un tercero imparcial llamado árbitro la resolución de su controversia, y éste, siguiendo el procedimiento determinado previamente por las partes decide la controversia mediante un «laudo arbitral» que es de obligatorio cumplimiento para las partes».

El arbitraje comparte con el proceso jurisdiccional su carácter heterocompositivo, por lo que su procedimiento se funda sobre los principios de contradicción, de audiencia y de igualdad entre las partes, a la vez que permite el adecuado ejercicio de defensa de sus derechos ${ }^{35}$. De ahí la importancia de la independencia e imparcialidad de los árbitros que van a resolver la controversia, manteniendo una posición neutral al igual que los jueces y tribunales ${ }^{36}$.

34 El señalado artículo determina que «la transacción tiene respecto de las partes, la misma eficacia y autoridad que la cosa juzgada», equiparando ese acuerdo de transacción a un título ejecutivo judicial. No obstante, el art. 600 párrafo segundo del CPCN dispone que "son títulos no judiciales de ejecución: [...] 4) Los laudos arbítrales, transacciones y acuerdos suscritos entre las partes originados por cualquiera de las formas alternas de resolución de conflictos».

35 Barona Vilar, Silvia 2011, 200.

36 Marcos González, María. 2004. «El sistema arbitral español de consumo en el marco normativo de la Unión Europa». La Ley, Revista jurídica española de doctrina, jurisprudencia y bibliografía. n. ${ }^{\circ}$ 2: 1679. San Cristóbal Reales, Susana. 2013. "Sistemas 
Atendiendo a lo estipulado en la LMA, los árbitros resolverán la cuestión litigiosa conforme a dos tipos de arbitrajes:

\section{a. Arbitraje de equidad}

El artículo 24 inciso e) de la LMA determina que el arbitraje de equidad «se da cuando el Tribunal Arbitral resuelve conforme a sus conocimientos profesionales y técnicos». En estos casos el tribunal «podrá estar integrado por profesionales expertos en la materia objeto de arbitraje, excepto lo que las partes dispongan para ese efecto» (art. 30 párrafo segundo LMA).

\section{b. Arbitraje de Derecho}

La regla general es que el arbitraje debe resolverse de equidad. No obstante, las partes en atención al principio de la autonomía de la voluntad pueden optar por el arbitraje de Derecho, que se define como aquel en que los árbitros resuelven la «cuestión controvertida con arreglo al derecho aplicable» [art. 24 inciso d) LMA]. En este supuesto el tribunal arbitral deberá estar compuesto "exclusivamente por abogados y resolverá las controversias con estricto apego a la ley aplicable» (art. 30 párrafo primero LMA).

\section{Procedimiento}

Por lo que respecta al procedimiento de arbitraje nicaragüense en líneas generales se sujeta a la siguiente estructura:

\section{a. Solicitud}

El artículo 47 párrafo primero de la LMA determina que salvo que las partes hayan convenido otra cosa, las actuaciones arbitrales se iniciarán en la fecha en que el demandado haya recibido el requerimiento de someter la controversia a arbitraje.

El requerimiento habrá de hacerse mediante forma escrita dirigido a la Institución competente, debiendo contener: «a) Nombre y generales de ley del demandante y demandado. b) La solicitud de someter a arbitraje la controversia. c) Copia autenticada del acuerdo

alternativos de resolución de conflictos: negociación, conciliación, mediación, arbitraje, en el ámbito civil y mercantil». Anuario jurídico y económico escurialense. n. ${ }^{\circ}$ 46: 57. 
arbitral o cláusula arbitral en que se ampara la solicitud, con referencia al contrato base de la controversia. d) Descripción general de la controversia que desea someter al arbitraje y las pretensiones del demandante. e) En caso de que las partes no hayan convenido el número de árbitro, una propuesta sobre el número de los mismos. f) Señalamiento de oficinas para oír notificaciones, en el lugar del arbitraje. g) La notificación referente al nombramiento al nombramiento del tercer arbitro».

Presentado el requerimiento ante la Institución competente, se conforma el Tribunal, momento en que comienza a transcurrir el plazo de diez días para presentar la demanda la cual, una vez se le ha dado traslado al demandado "deberá responder a todos los extremos alegados en la demanda so pena de declarar contestado de forma asertiva los extremos de la misma sobre los cuales el demandado no se haya pronunciado» (art. 49 LMA). El art. 51 párrafo segundo LMA señala que «si el demandado no presenta su contestación de conformidad con lo dispuesto por esta Ley, el tribunal arbitral, continuará las actuaciones, sin que esa omisión se considere por sí misma como una aceptación de las alegaciones del demandante».

\section{b. Pruebas}

La LMA permite abrir un periodo de prueba bien a petición de parte o a instancia del propio tribunal dentro del plazo que los propios árbitros determinen (art. 52 párrafo final LMA). Tras la presentación de las pruebas, únicamente resta ya su práctica. A este respecto el art. 50 párrafo primero de la LMA preceptúa «salvo acuerdo en contrario de las partes, el tribunal arbitral decidirá si han de celebrarse audiencias para la presentación de pruebas o para alegatos orales, o si las actuaciones se sustanciarán sobre la base de documentos y demás pruebas».

\section{c. Celebración de audiencia. Procedencia e improcedencia}

La posibilidad de celebrar audiencia se subordina en la LMA bien al hecho de que la parte haya propuesto prueba que deba ser practicada bajo la inmediación del tribunal arbitral o a solicitud de ambas partes siempre que el tribunal lo estime necesario (art. 50 LMA). No obstante, la norma del art. 50 párrafo primero in fine de la LMA determina que «si las partes hubiesen convenido en que no se celebre audiencia, el Tribunal arbitral celebrará dichas audiencias en la fase más apropiada de las actuaciones a petición de las partes». 
En este momento, formuladas ya la totalidad de las alegaciones de las partes, se abre para el tribunal arbitral una doble posibilidad: bien la de continuar con el procedimiento mediante la celebración de una audiencia oral o bien la de poner término al mismo con el señalamiento de una fecha para dictar el laudo.

\section{d. Conclusión}

El arbitraje se dará por concluido de conformidad con el art. 58 de la LMA con una de las siguientes posibilidades:

\section{i. Emisión del laudo}

El laudo es el modo normal y ordinario de finalización del proceso arbitral que resuelve de forma definitiva la controversia. El laudo deberá dictarse en el plazo que las partes hayan convenido o en su defecto en el plazo de seis meses «contados a partir de la integración del Tribunal arbitral» (art. 57 párrafo primero LMA). El contenido del laudo se decide por mayoría de votos y se dicta por escrito, debiendo contener los requisitos que exige el artículo 57 de la LMA.

Esta resolución será firmada por todos los árbitros, pudiéndose hacer constar las opiniones discrepantes, y se acordará su notificación fehaciente a las partes, momento a partir del cual empieza a contar el plazo para presentar el único «recurso» posible, el de anulación, transcurrido el cual el laudo alcanzará firmeza y con ella los efectos típicos del mismo: cosa juzgada y ejecutoriedad. En este sentido, el laudo arbitral firme produce efectos idénticos al de la cosa juzgada de acuerdo con lo que establece la legislación procesal civil para las sentencias judiciales firmes.

\section{ii. Desistimiento}

Nos encontramos ante lo que la doctrina denomina «forma anormal de terminación del proceso» ${ }^{37}$ por cuanto no sigue el desarrollo o esquema ordinario del procedimiento en sus sucesivas fases de alegación, prueba y decisión.

En este sentido, el párrafo segundo del art. 53 de la LMA señala que «mediante comunicación escrita a los árbitros, la parte deman-

37 Rifá Soler, José María. Manuel Richard González e Iñaki Riaño Brun. 2010. Derecho procesal civil, Pamplona: Publicaciones Gobierno de Navarra e Instituto Navarro de Administración Pública. 
dante puede desistir del arbitraje, en cualquier momento, antes de la notificación del laudo. En este caso y salvo pacto en contrario, todos los gastos del arbitraje y las remuneraciones de los árbitros serán asumidos por dicha parte» ${ }^{38}$.

En este supuesto se está ante un desistimiento unilateral que es producido por la voluntad única del demandante en cualquier momento del proceso arbitral. Junto al desistimiento unilateral se contempla el desistimiento bilateral que ocurre cuando ambas partes le manifiestan al tribunal que ya no desean continuar con el proceso arbitral (art. 58 párrafo tercero LMA).

\section{iii. Transacción}

Otra forma de terminación anormal del proceso arbitral es la transacción, la cual consiste en aquel negocio jurídico bilateral que «tiene la misma naturaleza y efectos que cualquier laudo dictado sobre el fondo del litigio» (art. 56 LMA), que produce todos los efectos de la cosa juzgada y que, en caso de incumplimiento, es susceptible de ejecución forzosa 39 .

\section{Problemática que se suscita en la ejecución del laudo arbitral}

Como es sabido el laudo arbitral al igual que las sentencias judiciales tiene eficacia de cosa juzgada, es decir, se convierte en título ejecutivo judicial. De tal manera que, si el obligado incumple voluntariamente lo estipulado en el laudo, la parte legitimada procede a solicitar la ejecución forzosa en base a un título judicial ${ }^{40}$. No obstante, la ejecución del laudo arbitral en el ordenamiento jurídico nicaragüense genera cierta problemática que a continuación se aborda:

38 A este respecto el art. 58 párrafo segundo de la misma ley determina que: «El tribunal arbitral podrá también ordenar la terminación de las actuaciones arbitrales cuando el demandante retire su demanda, a menos que el demandado se oponga a ello y el tribunal arbitral reconozca un legítimo interés de su parte en obtener una resolución definitiva del litigio».

39 De La Oliva Santos, Andrés. Ignacio Díez-Picazo Giménez. y Jaime Vegas Torres. 2016. Derecho procesal civil. Madrid: Editorial Universitaria Ramón Areces. En el mismo sentido, Tórrez Peralta, William. 2017. Derecho procesal civil (Conforme al nuevo Código Procesal Civil). Managua: Gutenberg Impresiones.

40 Barona Vilar, Silvia 2011, 199. Ripol Carulla, Ignacio. 2013. «La suspensión de la ejecución del laudo: Estudio del art. 45. LA». Justicia, Revista de Derecho procesal, n. ${ }^{\circ} 1: 381$. 


\subsection{La firmeza del laudo. El denominado «recurso de nulidad» del laudo}

El artículo 62 párrafo primero de la LMA, bajo la rúbrica de «Reconocimiento y Ejecución», dispone que "un laudo arbitral, cualquiera que sea el país en que se haya dictado, será reconocido como vinculante y, tras la presentación de una petición por escrito al tribunal competente, será ejecutado en conformidad con las disposiciones establecidas en la presente Ley y demás leyes de la materia».

El laudo es una resolución equiparable a título ejecutivo judicial $y$, por tanto, directamente ejecutable. Sin embargo, la norma nicaragüense permite al juez aplazar dicha ejecución. Esta ley mantiene un error terminológico de principio, ante el cual elabora una regulación que resulta híbrida entre el laudo arbitral y el denominado «recurso de nulidad», lo cual tiene efectos directos en el procedimiento de ejecución y, por tanto, tiene consecuencias fundamentales en la consideración de este ADR como un método efectivo, rápido y garante.

La practicabilidad del laudo contrasta con una sentencia judicial cuya ejecución podría verse dilatada en base a la interposición de recursos contra la misma. Los laudos arbitrales, por su propia naturaleza ${ }^{41}$, son irrecurribles y únicamente sujetos a una acción de anulabilidad en vía jurisdiccional. De este modo lo explica claramente BARONA VILAR cuando señala que «la acción de anulación no es equiparable a un recurso ni tiene tal naturaleza, la pendencia de un recurso como presupuesto de la ejecución provisional no existe en el ámbito del arbitraje y no puede considerarse otra ejecución» ${ }^{42}$. Siguiendo con la autora, la "acción de anulabilidad» da lugar a un proceso declarativo autónomo, en el que su pretensión es dejar sin efecto el laudo, siempre y cuando se cumpla alguno de los motivos tasados por la ley ${ }^{43}$.

La LMA al regular la impugnación del laudo menciona en su artículo 61, de forma equivocada a nuestro parecer y contraviniendo la doctrina mayoritaria, el «recurso de nulidad como único recurso contra un laudo arbitral» ${ }^{44}$. Partiendo de esta consideración, en su

41 Barona Vilar, Silvia. 2011. «Comentario al artículo 43». En Comentarios a la Ley de Arbitraje, 1488-1489. Madrid: Civitas.

42 Barona Vilar, Silvia 2011, 1489.

43 Barona Vilar, Silvia 2011, 1507.

44 El propio Código Procesal Civil de 2015 ahonda en el error y utiliza la misma terminología que la LMA cuando señala expresamente que «procede el recurso de nulidad contra el laudo arbitral ante la Sala de lo Civil de la Corte Suprema de Justicia al tenor de la ley de la materia». 
artículo 63 dispone que: «Si se ha pedido a un tribunal jurisdiccional, la nulidad o la suspensión del laudo, el tribunal al que se pide el reconocimiento o la ejecución podrá, si lo considera procedente, aplazar su decisión y podrá también ordenar a la otra parte que dé garantías apropiadas, todo a instancia de la parte que pida el reconocimiento o la ejecución del laudo».

En base a esta disposición, el laudo arbitral ya no es directamente ejecutable sino que depende de la voluntad judicial. De este modo, consideramos, hace "añicos» uno de los principios básicos del arbitraje.

La ausencia de firmeza de la resolución arbitral se verifica, además, por la ausencia en la norma de ninguna referencia a esta circunstancia, tampoco a su consideración de cosa juzgada. En este sentido, el artículo 58 de la LMA únicamente señala que «las actuaciones arbitrales terminan con el laudo definitivo». ${ }^{45} \mathrm{~A}$ pesar de ello, reiteramos que el laudo arbitral, por naturaleza, es firme y ejecutable desde su emisión y no desde la resolución de una acción de nulidad ni de la interposición de dicha acción, como así lo define mayoritariamente la doctrina.

En cualquier caso, con el ejercicio del mal llamado «recurso de nulidad» se debería iniciar un nuevo proceso independiente del arbitral en virtud del cual se someterá a los órganos jurisdiccionales el examen de la legalidad del procedimiento arbitral, alumbrando un procedimiento autónomo y distinto del que trae causa, y que en la LMA solo podrían suscitarse en base a las causales señaladas en su artículo $^{46}$ y que versan sobre la legalidad y validez que pueda darse al laudo impugnado.

45 El laudo no debe sujetarse a la diferenciación que se establece para las sentencias y que en la norma procesal viene regulada en el artículo 192 del CPCN: "Son resoluciones definitivas las que ponen fin a la primera y a la segunda instancia». Y el art. 193 del mismo Código: "Son resoluciones firmes aquellas contra las que no cabe recurso alguno, bien por no preverlo la ley, o porque estando previsto, transcurrió el plazo legalmente fijado, sin que ninguna de las partes lo haya presentado; o porque habiéndolo presentado, desistiera el recurrente, o porque no hubiera sido admitido». Ya que, finalizada la instancia arbitral finaliza en sí el arbitraje.

46 El artículo 61 de la LMA expresa que el «laudo arbitral solo podrá ser anulado por la Sala Civil de la Corte Suprema de Justicia cuando: 1) La parte que interpone la petición pruebe: a) Que una de las partes en el acuerdo de arbitraje, estaba afectada por alguna incapacidad que vició su voluntad, o que dicho acuerdo no es válido en virtud de la ley a que las partes lo han sometido, o si nada se hubiera indicado a este respecto, en virtud de la ley del país en que se haya dictado el laudo; b) Que no ha sido debidamente notificada de la designación de un árbitro o de las actuaciones arbitrales, o no ha podido por cualquier otra razón, hacer valer sus derechos; c) Que el laudo se 
Este proceso autónomo se abre con una primera y única instancia ante la Sala Civil de la Corte Suprema de Justicia: primera, en tanto que antes de esta no se había desarrollado actividad judicial alguna con respecto a este objeto; y única por cuanto que contra la resolución de la Corte Suprema que ponga fin al proceso de impugnación del laudo no cabe recurso alguno.

\subsection{El laudo arbitral en la norma nicaragüense como título ejecutivo extrajudicial}

Es sabido que un título ejecutivo es el presupuesto básico para iniciar la actividad de ejecución forzosa, en cuanto del mismo se deduce que el acreedor tiene derecho al despacho de ejecución. Por tanto, el título de ejecución es aquel documento en el que consta la obligación de la parte contra la cual se ha de dirigir el proceso de ejecución ${ }^{47}$.

La LMA dedica los arts. 62 y 63 de su título VIII a la ejecución del laudo. El art. 62 es una norma de remisión al señalar que el laudo "será ejecutado en conformidad con las disposiciones establecidas en la presente Ley y demás leyes de la materia», es decir a lo dispuesto en el Código Procesal Civil sobre la ejecución forzosa.

El CPCN, norma moderna inspirada en la LEC de España de 2000, recoge en su Libro Sexto la ejecución forzosa tanto de títulos judiciales como de títulos extrajudiciales (arts. 595 a 771). Sin embargo, a diferencia del texto procesal civil español que unifica el procedimiento para ambos títulos ejecutivos, la norma nicaragüense distingue dos clases

refiere a una controversia no prevista en el acuerdo de arbitraje o contiene decisiones que exceden los términos del acuerdo de arbitraje; no obstante, si las disposiciones del laudo que se refieren a las cuestiones sometidas al arbitraje pueden separarse de las que no lo están, solo se podrán anular estas últimas; o d) Que la composición del tribunal arbitral o el procedimiento arbitral no se han ajustado al acuerdo entre las partes, salvo que dicho acuerdo estuviera en conflicto con una disposición de esta Ley de la que las partes no pudieran apartarse o, falta de dicho acuerdo, que no se han ajustado a esta Ley. 2) O cuando el tribunal compruebe: a) Que, según la ley de este Estado, el objeto de la controversia no es susceptible de arbitraje; o b) Que el laudo es contrario al orden público del Estado nicaragüense. También se declarará nulo un laudo arbitral cuando este no se haya dictado dentro del plazo establecido por las partes o en su defecto según lo establecido en la presente Ley».

47 Asencio Mellado, José María, Olga Fuente Soriano, y Otros. 2019. Derecho procesal civil. Parte especial. Valencia: Tirant lo Blanch. En el mismo sentido, Torrez Peralta, William 2017, 500. 
de procesos de ejecución forzosa, atendiendo a si el título es judicial (arts. 612 a 640) o extrajudicial (arts. 641 a 660).

El artículo 600 del CPCN establece la clasificación de los títulos ejecutivos entre judiciales y no judiciales. Serán títulos judiciales de ejecución aquellas resoluciones firmes de condena dictadas tras el correspondiente proceso de declaración, a las que, a estos efectos, se equiparán los autos que conforme el Código Procesal Civil u otras leyes lleven aparejada ejecución y las sentencias de homologación de transacciones y acuerdos durante el proceso. Son títulos no judiciales todos los demás a los que por disposición legal expresa se les atribuye fuerza ejecutiva, entre ellos los «laudos arbitrales» ${ }^{48}$ [art. 600 párrafo segundo numeral 4) CPCN].

De lo anterior podemos observar que el legislador procesal nicaragüense considera al laudo un título ejecutivo extrajudicial. Esta decisión de asumir el laudo como título no judicial tiene devastadoras consecuencias para la propia institución del arbitraje, que se erigió como fórmula equiparable a un título judicial, dotada de la misma seguridad jurídica, con efectos de cosa juzgada material.

El artículo 659 del CPCN afirma que las «resoluciones dictadas en los procesos ejecutivos de títulos no judiciales no producirán efecto de cosa juzgada sobre derechos que no fueron debatidos, quedando a salvo el derecho de las partes para promover el proceso declarativo que corresponda». Efectivamente, únicamente hace referencia a

48 Es únicamente en Nicaragua en comparación con el resto de los países lberoamericanos, en que se estipula que la ejecución del laudo arbitral se hará por los cauces del proceso de ejecución de títulos extrajudiciales. En las otras legislaciones de la región, el laudo arbitral se ejecuta en vía de ejecución de títulos judiciales o asimilados, como es el caso de los siguientes países: México (art. 504 de la Ley s/n de 29 de agosto de 1932 de Código de Procedimientos Civiles para la Ciudad de México), Guatemala (art. 294. $2^{\circ}$ del Decreto-Ley 107/1963 de 14 de septiembre de Código Procesal Civil y Mercantil), El Salvador (art. 554. $2^{\circ}$ del Decreto-Legislativo 712/2008 de 14 de noviembre de Código Procesal Civil y Mercantil), Honduras (art. 751.2 del Decreto 211/2006 de 22 de enero de Código Procesal Civil), Costa Rica (art. 99.1 de la Ley 9342/2016 de 3 de febrero de Código Procesal Civil), Panamá (art. 69 párrafo primero de la Ley 131/2013 de 31 de diciembre de Ley que Regula el Arbitraje Comercial Nacional e Internacional), Ecuador (art. 363.2 Ley s/n de 12 de mayo de 2015 de Código Orgánico General del Proceso), Perú (art. 713.2 del Decreto-Ley 768/1992 de 8 de enero de Código Procesal Civil), Bolivia (art. 404.6 de la Ley 439/2013 de 19 de noviembre de Código Procesal Civil), Paraguay (art. 519 de la Ley 1337/1988 de 20 de octubre de Código Procesal Civil), Uruguay (art. 498.1 de la Ley 15.982/1988 de 18 de octubre de Código General del Proceso), Argentina (art. 499 párrafo primero de la Ley 17.454/1967 de 15 de septiembre de Código Procesal Civil y Comercial de la Nación) y España (art. 517.2.2. de la Ley de 7 de enero de 2000 de Enjuiciamiento Civil). 
aquellos «derecho que no fueron debatidos en el proceso de ejecución». Aún así, abre la «puerta» al inicio de un nuevo procedimiento con las consecuencias que todo proceso conlleva: tiempo, costes e incertidumbre.

Como se puede ver, el precepto citado trastoca lo que se viene afirmando anteriormente sobre los efectos de la cosa juzgada material $^{49}$ que produce el laudo arbitral definitivo (art. 58 párrafo primero LMA). Esto lo que viene a crear es incertidumbre a las partes que se someten al arbitraje lo que se traduce en falta de seguridad jurídica, porque de acuerdo con el art. 659 del CPCN, lo ejecutado en los títulos extrajudiciales, entre ellos el «laudo arbitral», les deja a las partes la vía abierta una vez concluida la ejecución forzosa para hacer uso del proceso declarativo correspondiente. Todo ello deja como consecuencia la privación de cosa juzgada material del laudo. Se trata, por tanto, de una decisión desacertada del legislador ya que la vinculación jurídica del laudo al igual que la sentencia está contenida en los efectos positivos y negativos de la cosa juzgada material.

A pesar de lo anterior, compartimos la opinión de la doctrina, en este caso, unánime, con respecto a esta situación y que queda perfectamente reflejada en las consideraciones que sobre el tema ha hecho PARDO IRANZO50, en el sentido de que el resultado de un proceso arbitral tiene un valor semejante al que concede el proceso jurisdiccional, puesto que la autonomía de la voluntad de las partes les permite, cuando se trate de materias dispositivas, acudir a formas de solución de conflictos entre ellos, los heterocompositivos, como el arbitraje, distintos del proceso jurisdiccional, pero con resultados vinculantes como si ante los tribunales de justicia hubieran acudido.

49 Recuérdese que la cosa juzgada material es la imposibilidad de obtener en otro proceso un resultado contrario al obtenido en una sentencia judicial firme. Su eficacia, despliega dos efectos distintos. Por un lado, un efecto «negativo» o excluyente, que supone la exclusión cuanto antes un segundo proceso con el mismo objeto ya decidido mediante sentencia firme en un proceso anterior (art. 210 párrafo primero (PCN). Es el tradicional non bis in ídem. Por otro lado, un efecto "positivo» o prejudicial, vinculando al tribunal de un proceso ulterior entre las mismas partes con objeto conexo, a estar a lo ya decidido si constituye un antecedente o presupuesto lógico de lo que haya de resolverse (art. 210 párrafo quinto CPCN). Bernardo San José, Alicia. 2008. "Principales efectos del laudo arbitral: cosa juzgada y ejecutabilidad». Revista de arbitraje comercial y de inversiones. 1: 116. https://arbitrajeraci.files.wordpress.com/2018/08/principales-efectos-del-laudo-arbitral-cosa-juzgada-y-ejecutabilidad.pdf

50 Pardo Iranzo, Virginia. 2011. «Comentario al artículo 44». En Comentarios a la Ley de Arbitraje, 1524. Madrid: Civitas. 


\section{La resolución de conflictos en la legislación cooperativa nicaragüense}

\subsection{Breve evolución de los mecanismos alternos de solución de conflictos en el Derecho cooperativo}

Los ADR son figuras prácticamente nuevas en el Derecho cooperativo nicaragüense. El Decreto 1949/1914 de 30 de abril de Código de Comercio $^{51}$ que fue la primera norma reguladora de las cooperativas no hace ninguna alusión a estos mecanismos. Lo mismo sucede con el Decreto 1833/1971 de 17 de junio, de Ley General de Cooperativas ${ }^{52}$, que fue aprobada durante el régimen somocista (1936-1979).

Tampoco el Decreto 826/1981 de 17 de septiembre, de Ley de Cooperativas Agropecuarias ${ }^{53}$, dictada en la época revolucionaria (1979-1990). Ni en la Ley 84/1990 de 24 de marzo, de Cooperativas Agropecuarias y Agroindustriales ${ }^{54}$ aprobada en la transición política (1990-1995)55.

Ahora bien, la presión del movimiento obrero nicaragüense significó para el régimen somocista una toma de "conciencia» en orden al establecimiento de medidas protectoras de la clase trabajadora. El somocismo hizo suyas las reivindicaciones de los trabajadores, intercediendo en las relaciones laborales tanto individuales como colectivas. $Y$ esto el régimen lo concibió en el fondo para frenear y neutralizar el avance del Partido Socialista, el cual contaba ya con mucha influencia en la clase trabajadora desde inicio de los años $40^{56}$. Fue en este contexto en que se aprobó la Ley 336/1945 de 12 de enero de Código del Trabajo57 (CT, en adelante).

El CT regulaba en su Capítulo IV del Libro Cuarto a las cooperativas. En este orden de cosas el art. 210 disponía: «Cooperativa es

51 La Gaceta Diario Oficial n. ${ }^{\circ} 248$ de 30 de octubre de 1916.

52 La Gaceta Diario Oficial n. ${ }^{\circ} 164$ de 23 de julio de 1971.

53 La Gaceta Diario Oficial n. ${ }^{\circ} 222$ de 2 de octubre de 1981.

54 La Gaceta Diario Oficial n. ${ }^{\circ} 62$ de 28 de marzo de 1990.

55 Torrez Peralta, William. 2020. «El derecho cooperativo nicaragüense como instrumento de desarrollo social». Boletín de la asociación internacional de Derecho cooperativo n. $^{\circ}$ 57: 335.

56 Gould, Jeffrey. 1985. «Amigos peligrosos, enemigos mortales: Un análisis de Somoza y el movimiento obrero nicaragüense (1944-1946). Revista de historia. n. ${ }^{\circ} 12-13$ : 20. https://www.revistas.una.ac.cr/index.php/historia/article/view/3189

57 La Gaceta Diario Oficial n. ${ }^{\circ} 23$ de 1 de febrero de 1945. Este CT fue derogado por la Ley 185/1996 de 5 de septiembre, de Código del Trabajo. La Gaceta Diario Oficial n. ${ }^{\circ} 205$ de 30 de octubre de 1996. 
toda sociedad de duración indefinida y de personal y capital variable e ilimitado que los asociados organizar en común y con objeto determinado regulando sus actividades e intereses individuales a fin de realizar su progreso económico y social sin ánimo de lucro y sobre la base, distribución de saldos o excedentes a prorrata de la utilización que cada uno haga de la función social». Y el art. 211 del mismo Código dispuso que el Ministerio del Trabajo era el ente encargado de promover, organizar y aprobar las cooperativas. Fue precisamente esta Ley la que estableció por primera vez los ADR en el Derecho cooperativo nicaragüense.

En este sentido, el artículo 251 del CT determinaba que «todo conflicto colectivo de carácter económico social debe someterse obligatoriamente a la Conciliación», creando para estos efectos las denominadas «Juntas Permanentes de Conciliación» (arts. 251 a 262 CT). Hágase notar que no estamos ante un presupuesto impuesto como carácter previo sino ante una ADR que se establece como única vía de resolver el conflicto.

Asimismo, se establecía el arbitraje, al prescribir el art. 263 CT: "Los Tribunales de Arbitraje, serán encargados de resolver los conflictos colectivos económicos sociales [...]». En los artículos de 264 a 267 se definían las funciones de este arbitraje.

Con la implementación tanto de la conciliación como el arbitraje en el CT se comenzaron a resolver las controversias que se producían entre cooperativas y estas con sus socios.

No obstante, con la aprobación de la Ley General de Cooperativas de 1971 se deroga todo lo referente al cooperativismo que establecía el $C T$, siendo que en su nueva regulación se omite cualquier referencia a la posibilidad de recurso a los ADR.

De todo lo anterior se puede decir que si bien es cierto que se produjo un avance al establecerse por primera vez una Ley General de Cooperativas, donde se determinan una serie de principios, derechos y deberes de sus asociados, también significó un retroceso en la implementación de los ADR tal y como la disponía el CT de 1945.

En definitiva, consideramos que le faltó beligerancia al movimiento cooperativo o quizá falta de asesoría jurídica para preservar los ADR como más afines al Derecho cooperativo, ausencia que se prolongó en las subsiguientes reformas. En este sentido entendemos que jugaron negativamente los intereses de los letrados quienes carentes de una cultura de negociación percibían en los ADR una amenaza a sus opciones y previsiones económicas. 


\subsection{La resolución de conflictos en la legislación cooperativa vigente}

La cooperativa como realidad social tiene unas características muy peculiares que vienen dadas desde las motivaciones para su creación como en la naturaleza de sus relaciones, conformando grupos en los que sus miembros comparten condiciones sociales, económicas y culturales con objetivos e intereses comunes. Y es así como la propia LGC vigente de 2004 en su artículo 5 las concibe al definir a la cooperativa como una "asociación autónoma de personas que se unen voluntariamente para hacer frente a sus necesidades y aspiraciones económicas, sociales y culturales comunes por medio de una empresa de propiedad conjunta y democráticamente controlada». Y a esto se le añaden los principios que rigen a las cooperativas y que vienen enumerados en el art. 8 de la misma norma, tales como autoayuda, igualdad, democracia, equidad, responsabilidad y solidaridad ${ }^{58}$.

A pesar de esta base de condiciones similares, la cooperativa está expuesta a que se susciten conflictos en cualquier momento y puedan presentarse divergencias tanto internas como externas, pues como señala MORENO CATENA las sociedades sin conflicto son una utopía59. La misma gestión democrática de la cooperativa es fuente de conflictos produciéndose, por tanto, abundantes disputas en relación a su funcionamiento y desarrollo60.

Dado que se trata, en la mayoría de los casos, de organizaciones cuyos miembros se sitúan en un estado general de vulnerabilidad, es que los conflictos pueden llegar a desencadenar situaciones irreversibles con costos significativos tanto individualmente como para toda la organización, ocasionando pérdidas económicas irreparables que difícilmente puedan superarse por otros medios. En otras ocasiones, las

58 Este concepto legal de la LGC reitera la definición de cooperativa que da la Alianza Cooperativa Internacional en su Declaración sobre la Identidad Cooperativa aprobada en Manchester en el Congreso de su centenario el 23 de septiembre de 1995 que define a la cooperativa como «una asociación autónoma de personas que se han unido de forma voluntaria para satisfacer sus necesidades economías, sociales y culturales en común mediante una empresa de propiedad conjunta y de gestión democrática». Morillas Jarillo, María José. y Manuel Ignacio Feliú Rey. 2018. Curso de cooperativas. T. I. Madrid. Tecnos.

59 Moreno Catena, Víctor. y Valentín Cortes Domínguez. 2017. Introducción al Derecho Procesal. Valencia: Tirant lo Blanch.

60 Ordeñana Gezuraga, Ixusco. 2012. «Más allá del arbitraje cooperativo: la mediación cooperativa. Sobre la necesidad de fomentarla en el ordenamiento jurídico español a la luz del Real Decreto-Ley 5/2012, de 5 de marzo, de mediación en asuntos civiles y mercantiles». Revista Vasca de Economía Social-GEZKI 8: 112. https://ojs.ehu.eus/index. php/gezki/article/view/12719/0 
pérdidas y perjuicios pueden afectar a toda una comunidad. Es igualmente en razón a esta situación de vulnerabilidad que métodos rápidos que además supongan un ahorro de costos y desgaste responden de modo más conveniente a esta realidad.

Es por ello que el Estado debería preocuparse de forma más intensa por métodos de resolución de controversias más acordes con la realidad de las cooperativas, que constituyen una forma resolutiva, rápida y de bajo coste que no pongan en peligro no solo la propia existencia de la cooperativa sino su mantenimiento y funcionalidad.

Sin embargo, y lamentablemente, no encontramos en el Derecho cooperativo nicaragüense ninguna norma que expresamente señale el uso de los ADR, limitándose únicamente la LGC a indicar en su artículo 20 que: «El estatuto de la cooperativa deberá tener como mínimo las siguientes disposiciones: [...] e) procedimiento para resolver diferencias o conflictos dirimibles entre los asociados o entre estos y la cooperativa por causa o por ocasión de actos cooperativos» ${ }^{61}$. Tampoco señala nada al regular las funciones del Instituto Nicaragüense de Fomento Cooperativo ${ }^{62}$ (en lo sucesivo, INFOCOOP), como ente rector de la polí-

61 Según el art. 7 de la LGC se entiende por actos cooperativos «los que realizan los asociados entre sí y la cooperativa en cumplimiento de sus objetivos, las relaciones de las cooperativas con terceras personas no sujetas a esta Ley no son actos cooperativos y se regirán por la legislación correspondiente».

62 De conformidad con el artículo 114 de la LGC, son atribuciones y funciones de este instituto sin perjuicio de las demás que le otorgue la presente ley y su reglamento: a) promover, planificar y ejecutar las políticas nacionales en materia cooperativa, para fomento, capacitación y promoción del cooperativismo. b) autorizar y certificar la constitución y funcionamiento de las cooperativas conforme con los requisitos legales e inscribirlas en el Registro Nacional de Cooperativas. c) certificar cambios y actualizaciones que soliciten las cooperativas en el marco de esta ley y su reglamento. d) velar porque las cooperativas cumplan con las disposiciones legales y los principios cooperativos en función de su correcta administración, pudiendo realizar inspecciones o auditoría cuando lo estime conveniente. e) atender gestiones y demandas de las cooperativas y/o de sus asociados. f) requerir documentación para realizar investigaciones en las cooperativas, a solicitud de parte o de oficio. g) asistir a las sesiones de asamblea general de las cooperativas, a solicitud de parte o de oficio. h) actualizar la estadística de registro y crear un Centro Nacional de Documentación Cooperativa. i) coordinar su labor con otros organismos nacionales e internacionales, por razón de las actividades cooperativas. j) aprobar, revocar o suspender las resoluciones de los órganos sociales de la cooperativa, cuando estas fueran contrarias a la presente ley, a su reglamento, al estatuto y a su reglamento interno. k) cancelar las personalidades jurídicas, de oficio a solicitud de parte que lo justifique, así como disolver y liquidar la cooperativa cuando se compruebe que cometió o comete infracciones o violaciones fragantes a esta ley y su reglamento. I) asistir y auxiliar oportunamente a los asociados, cuando se considere que se está lesionando los intereses de la cooperativa y/o se ponga en grave peligro la propia existencia de la misma. m) investigar, sistematizar y divulgar información de experiencias que for- 
tica nacional de protección, fomento y desarrollo cooperativo (art. 113 LGC).

Por su parte, tampoco el Decreto-Ejecutivo 91/2007 de 10 de septiembre del Reglamento de la LGC determina nada al respecto ${ }^{63}$.

Como puede observarse, la legislación cooperativa nicaragüense no prevé ni hace referencia a los $A D R$, aunque nada impide que en los propios estatutos sociales se incorpore alguna de las formas existentes ya sea el arbitraje, la mediación y la conciliación.

En Nicaragua no contamos con estudios empíricos sobre el uso de los ADR en el Derecho cooperativo. De los escasos estatutos consultados, puedo afirmar que no he encontrado en ninguno de ellos mención alguna a los ADR, apareciendo en todos ellos la fórmula tradicional de acudir a la vía jurisdiccional. Si bien es cierto que la poca información que dispongo no representa ningún porcentaje alto del universo de cooperativas existentes en Nicaragua, esta información me hace pensar que un buen número de los estatutos repita esta fórmula. Téngase en cuenta que en el procedimiento de constitución de la cooperativa participan abogados como asesores jurídicos de los asociados quienes, como ya señalamos anteriormente, no tienen una cultura negociadora siendo más conveniente para ellos, y en todos los sentidos, la vía jurisdiccional.

A pesar de lo anterior, las posibilidades de acudir a los ADR no se cierran con la omisión de estas o con el recurso directo a la vía jurisdiccional, estampada en los estatutos de las cooperativas. Este tipo de controversias se ventilan en la jurisdicción civil sujeta al Código Procesal Civil. Como señalamos en otra parte de este trabajo, con la aprobación de la Ley 902/2015 de 5 de agosto se impone la mediación previa como obligatoria para acudir a los tribunales.

Sin embargo, y siendo coherentes con nuestro planteamiento, el cual pretendemos llevar a sus límites, esta mediación que contempla

talezca el derecho y la jurisprudencia cooperativa en Nicaragua. n) facilitar y promover el acceso de las cooperativas a recursos financieros para capital de trabajo, inversión, diversificación y mercado de bienes y servicios. o) impulsar mecanismos de inteligencia de mercado en apoyo al movimiento cooperativo. p) fomentar y apoyar la participación de las cooperativas en la cogestión con empresas públicas y/o en forma directa para ofertar servicios básicos a la población que lo demande. q) convocar a asamblea general, de conformidad al artículo 61 de la presente ley. r) velar por el estricto cumplimiento de las disposiciones legales vigentes en materia cooperativa. s) autorizar a instituciones, organismos y organizaciones para que presten, el servicio de capacitación en el sector cooperativo. t) garantizar el fomento a las cooperativas. u) asociarse a otros organismos de integración internacional e incluso institutos de otros países.

63 La Gaceta Diario Oficial n. ${ }^{\circ} 174$ de 11 de septiembre de 2007. 
la norma procesal tampoco se hace efectiva. Si decíamos que la razón principal de la omisión de los ADR en los estatutos de las cooperativas era la asesoría letrada, resistente a las vías negociadoras, con más razón en el umbral de la entrada en la vía jurisdiccional se conformarán con este tipo de resolución.

Sin embargo, insistimos en que la vía jurisdiccional no parece casar demasiado bien con el espíritu cooperativo. La connotación de ajenidad con la que se sigue valorando a los jueces en esta materia, sumado a la burocracia, a la mecánica del sistema judicial caracterizado por tácticas combativas que ahondan en la confrontación de las partes contendientes, o a la rigidez de las formas y sentencias cuya efectividad puede demorarse en el tiempo, entre otros factores, la convierten en un medio no demasiado adecuado para resolver los conflictos en el ámbito de las cooperativas. En este sentido, la vía jurisdiccional rompe con la filosofía y elementos inspiradores que rigen el orden y la vida de la cooperativa: la necesidad en la prontitud para una resolución del conflicto, la tendencia a la colaboración entre los socios y la conciencia de pertenencia a la organización de estos y su funcionamiento democrático e igualitario reclaman formas de resolver sus conflictos que permitan resarcir pronto y de forma efectiva sus diferencias. Como indica ORDEÑANA GEZURAGA, la vía jurisdiccional se convierte «en un medio no demasiado adecuado para dilucidar el conflicto cooperativo» ${ }^{64}$.

Consciente el Poder judicial de Nicaragua de estas dificultades ha irrumpido realizando ingentes esfuerzos de información y formación de abogados sobre el objeto y finalidad de estos mecanismos de gestión de controversias, lo que además les va a proporcionar una nueva óptica a la hora de abordar los conflictos que puedan plantearles sus clientes. También ha coadyuvado a que en los últimos años en las Facultades de Derecho se esté impartiendo la asignatura de mecanismos alternativos de conflictos como materia obligatoria para intentar cambiar la visión clásica de la figura del abogado, para que éste complemente su función de litigante con la de un gestor de controversia, un asistente legal que habrá de aconsejar a su cliente acerca de cuál es el método que él entiende idóneo para resolver su problema concreto para lo cual no únicamente deberán tener en cuenta la norma legal sino otros factores como la naturaleza misma de la cooperativa, sus principios rectores, sus objetivos, pero también la atención a las variables económicas, sociales, culturales o de efectividad, realidades todas ellas que muchas veces el abogado deja fuera de sus previsiones jurídicas. Y es justa-

64 Ordeñana Gezuraga, Ixusco 2012, 113. 
mente por ello que los ADR se convierten en medios idóneos de resolución de conflictos para el entrono cooperativo ${ }^{65}$.

Es aquí donde es necesario que el INFOCOOP tome conciencia de esta situación y facilite a las cooperativas con asesoría jurídica, e incluso con medios, con formación e información sobre esta materia. Asimismo, el movimiento cooperativo a través del Consejo Nacional de Cooperativas (en adelante, CONACOOP), constituido como órgano de participación, información, consulta, asesoramiento, elaboración y presentación de propuestas de políticas y programas de fomento, promoción, educación, inversión y desarrollo de la organización cooperativa (art. 126 LGC), debe aportar, entendemos, su grano de arena a este respecto.

Por último, señalar que la aplicación de los ADR a la empresa cooperativa favorecerá también el cumplimiento de los principios que proclama tanto la Alianza Cooperativa Internacional como la legislación cooperativa nicaragüense (art. 8 LGC), que como indica ARGUDO PÉRIZ, «favorece una mayor gestión democrática y participación de los socios, la necesaria educación y formación de los mismos, la cooperación entre cooperativas y la implicación y colaboración con la comunidad» 66 .

\section{Referencias generales sobre la resolución de conflictos en el Derecho cooperativo Iberoamericano}

Dentro de este apartado se va a destacar brevemente lo que determinan algunas legislaciones cooperativas en el entorno Iberoamericano en cuanto al uso de los ADR. Entre estos ordenamientos están los de México, Costa Rica, Panamá, Colombia y Bolivia.

\subsection{México}

El ordenamiento mexicano en su la Ley General de Sociedades Cooperativas, de 29 de julio de 1994, recoge en su regulación qué deben contener los estatutos de las cooperativas, en concreto en su artículo 16 con el siguiente tenor: "Las bases constitutivas de las sociedades cooperativas contendrán: [...] XI.- Derechos y obligaciones de los

65 Martí Miravalls, Jaume. 2005. «El Arbitraje Cooperativo en la Legislación Española». Boletín de la asociación internacional de Derecho cooperativo n. ${ }^{\circ}$ 39: 34.

66 Argudo Périz, José Luis 2006, 51. 
socios, así como mecanismos de conciliación y arbitraje en caso de conflicto sobre el particular». Como puede apreciarse la normativa mexicana de cooperativas obligas a los socios a establecer expresamente mecanismos alternos de resolución de controversias.

Cabe hacer mención también que la norma mexicana determina en su art. 65, que cuando en las sociedades cooperativas de productores haya conflicto por necesidades de expansión admitir a más socios, el Consejo de Administración tendrá la obligación de emitir una convocatoria para tal efecto, teniendo preferencia para ello, sus trabajadores, a quienes se les valorará por su antigüedad, desempeño, capacidad y en su caso por su especialización. "Ante una inconformidad en la selección, el afectado podrá acudir ante la Comisión de Conciliación y Arbitraje de la propia sociedad cooperativa si es que la hay, la que deberá resolverle por escrito en un término no mayor de 20 días naturales, independientemente de poder ejercer la acción legal que corresponda».

Esta opción que plantea la norma de creación de una Comisión de Conciliación y Arbitraje al interior de la cooperativa será una solución que la veremos en otros países del entorno.

\subsection{Costa Rica}

La regulación de los mecanismos alternativos de conflictos dentro del cooperativismo costarricense, en la Ley 6756/1982, de 5 de mayo, de Asociaciones Cooperativas y de Creación del Instituto de Fomento Cooperativo, en su artículo 63 determina: "Las diferencias que se susciten entre la cooperativa y sus asociados, serán decididas por la autoridad judicial competente, pero los estatutos podrán establecer juntas arbitrales que las diriman en forma rápida y obligatoria debiendo integrarse en la forma y términos en que se constituyen los órganos administrativos».

Lo recogido en esta norma nos indica que se si bien es cierto que el conflicto entre la cooperativa y sus socios se resolverá vía jurisdiccional, no obstante, se abre la posibilidad de hacer uso en primera instancia de los ADR, siempre y cuando queden establecidos en los propios estatutos, su metodología y los términos en los cuales se constituiría el órgano creado a ese efecto, las llamadas «juntas arbitrales».

\subsection{Panamá}

En el ordenamiento panameño la Ley 17/1997, de 1 de mayo, de Régimen Especial de Cooperativas, en su art. 18 establece que «El esta- 
tuto de la cooperativa contendrá: [...] 7. El régimen de sanciones, causas y procedimientos».

La legislación cooperativa de Panamá deja a criterio de los asociados el procedimiento a seguir en caso de conflictos que se susciten en la cooperativa. Prácticamente es idéntico a la línea que sigue la Ley de Cooperativas de Nicaragua. Sin embargo, la Ley cooperativa panameña va más allá al determinar en su art. 30 «Podrán establecerse juntas arbitrales para la decisión, provisional o inmediata, sobre las diferencias que puedan ocurrir entre la cooperativa y sus asociados, o entre estos, siempre que dichas diferencias tengan relación con la cooperativa. Las decisiones de dichas juntas tendrán carácter transitorio y obligatorio, mientras no se dicte fallo revocatorio por la autoridad judicial competente. El término para recurrir judicialmente contra tales decisiones de las juntas es de un año contado a partir de la fecha del laudo arbitral. Pasado dicho término sin haberse recurrido en su contra, la decisión arbitral respectiva tendrá carácter definitivo y hará tránsito a cosa juzgada».

\subsection{Colombia}

En el sistema cooperativo colombiano, la Ley 79/1988 de 23 de diciembre, de actualización de la "Legislación Cooperativas», en su artículo 19, señala que «Los estatutos de toda cooperativa deberán contener: [...] 5. Procedimientos para resolver diferencias o conflictos transigibles entre los asociados o entre estos y la cooperativa, por causa o con ocasión de actos cooperativos».

Lo señalado en Colombia es similar a lo regulado en Nicaragua, legislaciones que regulan esta materia de forma general sin entrar a contemplar las modalidades para su resolución ni la creación de organismos al efecto.

\subsection{Bolivia}

El ordenamiento boliviano difiere del resto de los sistemas Iberoamericanos analizados. En este sentido, la Ley 356/2013, de 11 de abril, General de Cooperativas, dedica en su capítulo X a las «Resoluciones de Conflictos dentro del ámbito cooperativo». Así, el artículo 97 de la señalada ley prescribe: "Las cooperativas podrán establecer en su estatuto orgánico, mecanismos alternativos de solución de conflictos dentro el ámbito cooperativo, en el marco de la Ley de Arbitraje y Conciliación, ante las instancias previstas en la presente Ley». 
El artículo 98 de la misma norma refiere expresamente a la conciliación, al expresar: «I. La conciliación, como instancia previa, será adoptada por las asociadas y los asociados ante las Juntas de Conciliación establecidas en cada cooperativa, de acuerdo a su estatuto orgánico. II. En caso de existir conflictos entre cooperativas de segundo y tercer grado, la conciliación se efectuará ante las Juntas de Conciliación de las Federaciones. III. El Centro de Conciliación y Arbitraje de la Confederación Nacional de Cooperativas - CONCOBOL, resolverá los conflictos entre cooperativas de cuarto grado o aquellos no resueltos en los grados inferiores».

El arbitraje está igualmente regulado en la norma cooperativa boliviana. En su artículo 99 señala: «I. El Centro de Conciliación y Arbitraje de la Confederación Nacional de Cooperativas - CONCOBOL, resolverá los conflictos dentro el ámbito cooperativo. II. Su organización, composición y funcionamiento, será establecido mediante reglamento interno».

De lo anterior se desprende que la legislación boliviana se inspiró en los ordenamientos cooperativos autonómicos españoles, en concreto en la Ley 9/2018 de 30 de octubre de Sociedades Cooperativas de Extremadura. Bolivia tiene una de las legislaciones más avanzadas en materia de los ADR para el Derecho cooperativo Iberoamericano.

En definitiva, podemos claramente identificar dos sistemas diferenciados en relación a las diversas regulaciones que de los ADR se contienen en las legislaciones cooperativas de Iberoamérica que hemos analizado. Por un lado, nos encontramos con un modelo de regulación general, donde son los asociados de la cooperativa los que van a establecer en sus estatutos para resolver sus divergencias, modelo que predomina en México, Costa Rica, Panamá, Colombia y Nicaragua. Por otro lado, se presenta un modelo cuya Ley de Cooperativas regula el uso de los ADR de forma pormenorizada, tal como es el caso de Bolivia.

\section{Conclusiones}

A partir de lo expuesto en este artículo, podemos extraer las siguientes conclusiones:

Primera. El Derecho cooperativo es un derecho eminentemente social, cuya naturaleza responde a una necesidad de promoción de la economía en ámbitos que difieren enormemente de los intereses, condiciones y realidades de las grandes empresas. Los principios y valores propios que subyacen tanto detrás de la propia creación de la coo- 
perativa como al interior de estas, es decir, en las relaciones entre los socios, son condición fundamental para su correcto funcionamiento. Estos principios propios de las cooperativas son la democracia, la equidad, la igualdad, la solidaridad, la cooperación y el compromiso recíproco. Es por ello que un conflicto surgido en este ámbito no pueda tener la misma respuesta que otros surgidos en ámbitos no sujetos a estos valores. Los ADR se convierten en este sentido en una forma de resolución de conflictos que encaja perfectamente con esta realidad pues tienen como objetivo fortalecer una cultura de paz que permita la reconstrucción del tejido cooperativo más que su disolución.

Segunda. La adecuación del uso de estos métodos al ámbito de las cooperativas no únicamente hacen referencia a la propia filosofía que las imbuye sino también en términos prácticos, pues esto mecanismos son más eficaces por su rapidez y bajo coste lo que permite una verdadera actualización del derecho de los socios al derecho de acceso a la justicia.

Tercera. A pesar de lo anterior, y su indiscutible sintonía entre la cooperativa y los ADR, desde nuestro punto de vista, podría verse obstaculizada por una regulación compleja o incierta que desembocara en un mal uso, o incluso llevar a ser descartada por la propia cooperativa, prefiriendo, como hemos visto en algunos casos, la vía jurisdiccional con los costes y desventajas que conlleva acudir a los tribunales de justicia para la vida de la cooperativa.

Cuarta. En Nicaragua la regulación de los ADR se presenta de forma deficitaria, no tanto por su regulación como tal sino por la fácil entrada a agentes externos (letrados) que buscan judicializar los asuntos. Esta situación desemboca en una falta de aprovechamiento de estos mecanismos por sus actores principales, adoptando estos un papel secundario cuando se opta por la vía jurisdiccional.

Quinta. En Nicaragua son varias las instituciones que tienen como tarea principal impulsar el uso de los ADR como política pública (el INFOCOOP y la Dirección de Resolución Alterna de Conflictos del Poder judicial, la CONACOOP, entre otras). Si bien desde el ámbito del Estado se han hecho importantes esfuerzos en capacitación e infraestructura, muestra de ellos son las instituciones mencionadas, no obstante se sigue privilegiando, por diversos motivos, la vía jurisdiccional.

Sexta. En la ausencia de voluntad de construcción de una cultura de paz a nivel cooperativo convergen varios motivos, no imputables 
únicamente al propio movimiento. Desde nuestro punto de vista, si no el único, la razón más importante de este desuso es la asesoría que brindan los letrados a las cooperativas, quienes, consciente o inconscientemente, inducen a una vía que, para ellos, es más conocida, requiere conocimientos que solo ellos tienen y además les supone mejores perspectivas económicas.

Séptima. Hay que tener presente que no solo se trata establecer los ADR por dejarlos plasmados en una norma. Una deficiente regulación también puede dar al traste con los ADR. A diferencia de otras legislaciones, como Bolivia, la Ley General de Cooperativas de Nicaragua es de las normas más lacónicas. Si a esto le añadimos su deficiente regulación, se pierde una oportunidad de atraer a ciertos colectivos que puedan ver en él falta de seguridad jurídica e ineficacia. Este es el caso de la incorrecta regulación del arbitraje en su artículo 61 de la LMA en lo que respecta al mal llamado «recurso de nulidad» o la del precepto 600 párrafo segundo numeral 4) del Código Procesal Civil cuando otorga al laudo arbitral cualidad de «título ejecutivo no judicial».

Estas antinomias y deficiencias pueden hacer infructuosa la labor de los organismos encargadas de impulsar su uso, y de los propios cooperativistas que se decidan por su uso, al encontrarse con situaciones que hacen más complejo e injusto el proceso.

Octava. Ante estas situaciones, se recomienda una reforma a la norma nicaragüense en este ámbito que supla las deficiencias y fallas arriba mencionadas, que permitan una disposición más favorable a su adopción tanto para su elección como para su tratamiento.

\section{Bibliografía}

ARGUDO PÉRIZ, José Luis. 2006. «Los sistemas no adversariales de resolución de conflictos en la legislación cooperativa autonómica». Revista vasca de economía social-GEZKI 2: 105-130 106. https://ojs.ehu.eus/index.php/ Gezki/article/view/3296/2922

ASENCIO MELLADO, José María, Olga Fuente Soriano, y Otros. 2019. Derecho procesal civil. Parte especial. Valencia: Tirant lo Blanch.

BARONA VILAR, Silvia. 2011. "Comentario al artículo 43». En Comentarios a la Ley de Arbitraje, 1483-1523. Madrid: Civitas.

- 2011. "Las ADR en la justicia del siglo XXI, en especial la mediación». Revista de Derecho 1: 185-211. https://scielo.conicyt.cl/scielo.php?pid=S071 $897532011000100008 \&$ script=sci_arttext\&tIng=en 
- 2013. Mediación en asuntos civiles y mercantiles en España. Valencia: Tirant lo Blanch.

- 2014. «Integración de la mediación en el moderno concepto de Acces to Justice. Luces y sombras en Europa». Revista para el análisis del Derecho 4: 2-29. https://www.raco.cat/index.php/InDret/article/view/291746/380245

BERNARDO SAN JOSÉ, Alicia. 2008. «Principales efectos del laudo arbitral: cosa juzgada y ejecutabilidad». Revista de arbitraje comercial y de inversiones. 1: 115-138. https://arbitrajeraci.files.wordpress.com/2018/08/principales-efectos-del-laudo-arbitral-cosa-juzgada-y-ejecutabilidad.pdf

CAPPELLETTI, Mauro. y Bryant Garth. 1996. El acceso a la justicia. La tendencia en el mundo mundial para hacer efectivos los derechos. México: Fondo de Cultura Económica.

CARRETERO MORALES, Emiliano. 2016. La mediación civil y mercantil en el sistema de justicia Madrid: Dykinson.

DE LA OLIVA SANTOS, Andrés. Ignacio Díez-Picazo Giménez. y Jaime Vegas Torres. 2016. Derecho procesal civil. Madrid: Editorial Universitaria Ramón Areces.

DíEZ-PICAZO, Luis María. 2013. Sistema de derechos fundamentales. Pamplona: Civitas Ediciones.

DIRECCIÓN DE RESOLUCIÓN ALTERNA DE CONFLICTOS-CORTE SUPREMA DE JUSTICIA DE NICARAGUA. 2019. MANUAL CURSO BÁSICO DE MEDIACIÓN. MANAGUA: PUBLICACIONES PODER JUDICIAL.

GOULD, Jeffrey. 1985. «Amigos peligrosos, enemigos mortales: Un análisis de Somoza y el movimiento obrero nicaragüense (1944-1946). Revista de historia. n. ${ }^{\circ}$ 12-13: 19-65. https://www.revistas.una.ac.cr/index.php/historia/ article/view/3189

HERRERA DE LAS HERAS, Ramón. 2012. "La autonomía de la voluntad en el arbitraje y la mediación. Jurisprudencia constitucional española y experiencias en el ámbito de consumo». Revista de Derecho 12: 175-193. https://scielo.conicyt.cl/scielo.php?script=sci_arttext\&pid=S071809502012000100008

MARCOS GONZÁLEZ, María. 2004. «El sistema arbitral español de consumo en el marco normativo de la Unión Europa». La Ley, Revista jurídica española de doctrina, jurisprudencia y bibliografía. n. ${ }^{\circ}$ 2: 1676-1685.

MARTí MIRAVALLS, Jaume. 2005. «El Arbitraje Cooperativo en la Legislación Española». Boletín de la asociación internacional de Derecho cooperativo n. ${ }^{\circ}$ 39: 33-91.

MONTERO AROCA, Juan, Juan Luis Gómez Colomer, Silvia Barona Vilar y María Pía Calderón Cuadrado. 2017. Derecho jurisdiccional. Proceso civil. Valencia: Tirant lo Blanch.

MONTOYA MELGAR, Alfredo. 2020. Derecho del trabajo. Madrid: Tecnos.

MORENO CATENA, Víctor. y Valentín Cortes Domínguez. 2017. Introducción al Derecho Procesal. Valencia: Tirant lo Blanch.

ORDEÑANA GEZURAGA, Ixusco. 2012. "Más allá del arbitraje cooperativo: la mediación cooperativa. Sobre la necesidad de fomentarla en el ordenamiento jurídico español a la luz del Real Decreto-Ley 5/2012, de 5 de 
marzo, de mediación en asuntos civiles y mercantiles». Revista Vasca de Economía Social-GEZKI 8: 112-141. https://ojs.ehu.eus/index.php/gezki/article/view/12719/0

OTERO PARGA, Milagros. y Helena Sotelo Muñoz. 2007. Mediación y solución de conflictos, habilidades para una necesidad emergente. Madrid: Tecnos.

PARDO IRANZO, Virginia. 2011. "Comentario al artículo 44». En Comentarios a la Ley de Arbitraje, 1521-1547. Madrid: Civitas.

PÉREZ-VILLALOBOS, María Concepción. 2017. «Artículo 24.1 CE: Tutela judicial efectiva». En Derechos fundamentales, aspectos básicos y actuales. Santiago de Compostela: Andavira Editora.

RAMOS PÉREZ, María Eugenia. 2006. "La gestión de conflictos en las cooperativas». Revista vasca de economía social-GEZKI 2: 131-149. https://dialnet. unirioja.es/servlet/articulo?codigo $=2234218$

RIFÁ SOLER, José María. Manuel Richard González. e Iñaki Riaño Brun. 2010. Derecho procesal civil, Pamplona: Publicaciones Gobierno de Navarra e Instituto Navarro de Administración Pública.

SAN CRISTÓBAL REALES, Susana. 2013. "Sistemas alternativos de resolución de conflictos: negociación, conciliación, mediación, arbitraje, en el ámbito civil y mercantil». Anuario jurídico y económico escurialense. n. ${ }^{\circ}$ 46: 3962.

SOTELO MUÑOZ, Helena, Emiliano Carretero Morales y Cristina Ruiz López. 2017. Mediación y resolución de conflictos: Técnicas y ámbitos. Madrid: Tecnos.

TÓRREZ PERALTA, William. 2017. Derecho procesal civil (Conforme al nuevo Código Procesal Civil). Mangua: Gutenberg Impresiones.

- 2020. «El Derecho cooperativo nicaragüense como instrumento de desarrollo social». Boletín de la asociación internacional de Derecho cooperativo n. ${ }^{\circ}$ 57: 351-389. https://doi.org/10.18543/baidc-57-2020pp351-389.

VALIÑO CES, Almudena. 2019. "Más allá de los métodos alternativos clásicos al proceso judicial: otras formas de resolución de conflictos». En Cuadernos de Dereito actual 11: 201-224. http://www.cadernosdedereitoactual. es/ojs/index.php/cadernos/article/view/381

WORLD JUSTICE PROJECT. 2020. ÍNDICE DE ESTADO DE DERECHO 2020. WASHINGTON, DC. https://worldjusticeproject.org/sites/default/files/documents/WJP-Global-ROLI-Spanish.pdf 


\section{Derechos de autor}

El Boletín de la Asociación Internacional de Derecho Cooperativo es una revista de acceso abierto lo que significa que es de libre acceso en su integridad inmediatamente después de la publicación de cada número. Se permite su lectura, la búsqueda, descarga, distribución y reutilización legal en cualquier tipo de soporte sólo para fines no comerciales y según lo previsto por la ley; sin la previa autorización de la Editorial (Universidad de Deusto) o el autor, siempre que la obra original sea debidamente citada (número, año, páginas y DOI si procede) y cualquier cambio en el original esté claramente indicado.

\section{Copyright}

The International Association of Cooperative Law Journal is an Open Access journal which means that it is free for full and immediate access, reading, search, download, distribution, and lawful reuse in any medium only for non-commercial purposes, without prior permission from the Publisher or the author; provided the original work is properly cited and any changes to the original are clearly indicated. 